\title{
Endoscopic management of ampullary tumors: European Society of Gastrointestinal Endoscopy (ESGE) Guideline
}

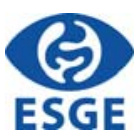

Authors

Geoffroy Vanbiervliet ${ }^{1}$, Marin Strijker ${ }^{2}$, Marianna Arvanitakis ${ }^{3}$, Arthur Aelvoet ${ }^{2}$, Urban Arnelo ${ }^{4}$, Torsten Beyna ${ }^{5} \odot$, Olivier Busch ${ }^{2}$, Pierre H. Deprez ${ }^{6} \odot$, Lumir Kunovsky ${ }^{7,8}$, Alberto Larghi ${ }^{9}$, Gianpiero Manes ${ }^{10} \odot$, Alan Moss ${ }^{11,12}$, Bertrand Napoleon ${ }^{13}$, Manu Nayar ${ }^{14}$, Enrique Pérez-Cuadrado-Robles ${ }^{15}$ ๑, Stefan Seewald ${ }^{16}$, Marc Barthet ${ }^{17} \odot$, Jeanin E. van Hooft ${ }^{18}$

Institutions

1 Department of Digestive Endoscopy, Centre Hospitalier Universitaire de Nice, Nice, France

2 Department of Surgery, Cancer Center Amsterdam, Amsterdam UMC, University of Amsterdam, Amsterdam, The Netherlands

3 Gastroenterology, Hepatopancreatology and Digestive Oncology, Erasme Hospital, Université Libre de Bruxelles, Brussels, Belgium

4 Department of Surgery, Centre for Digestive Diseases, Karolinska University Hospital, Stockholm, Sweden

5 Department of Gastroenterology, Evangelisches Krankenhaus Düsseldorf, Dusseldorf, NordrheinWestfalen, Germany

6 Gastroenterology and Hepatology Department, Cliniques universitaires Saint-Luc, Université Catholique de Louvain, Brussels, Belgium

7 Department of Gastroenterology and Internal Medicine, University Hospital Brno, Faculty of Medicine, Masaryk University, Brno, Czech Republic

8 Department of Surgery, University Hospital Brno, Faculty of Medicine, Masaryk University, Brno, Czech Republic

9 Digestive Endoscopy Unit, Fondazione Policlinico Universitario A. Gemelli IRCCS, Università Cattolica del Sacro Cuore, Rome, Italy

10 Aziende Socio Sanitaria Territoriale Rhodense, Gastroenterology, Garbagnate Milanese, Italy

11 Department of Endoscopic Services, Western Health, Melbourne, Australia

12 Department of Medicine, Western Health, Melbourne Medical School, University of Melbourne, Victoria, Australia

13 Service de Gastroentérologie, Hôpital Privé Jean Mermoz, Ramsay Générale de Santé, Lyon, France

14 Department of Gastroenterology, Freeman Hospital, Newcastle upon Tyne, UK
15 Department of Gastroenterology, Georges-Pompidou European Hospital, AP-HP Centre - Université de Paris, Paris, France

16 Gastroenterology Center, Klinik Hirslanden, Zurich, Switzerland

17 Department of Gastroenterology, Hôpital Nord, Assistance publique des hôpitaux de Marseille, Marseille, France

18 Department of Gastroenterology and Hepatology, Leiden University Medical Center, The Netherlands

published online 16.3 .2021

Bibliography

Endoscopy 2021; 53: 429-448

DOI 10.1055/a-1397-3198

ISSN 0013-726X

(C) 2021. European Society of Gastrointestinal Endoscopy All rights reserved.

This article ist published by Thieme.

Georg Thieme Verlag KG, Rüdigerstraße 14,

70469 Stuttgart, Germany

Appendix 1s

Supplementary material is available under https://doi.org/10.1055/a-1397-3198

\section{Corresponding author}

Geoffroy Vanbiervliet, MD PhD, Endoscopie Digestive, Hôpital L'Archet 2, Centre Hospitalier Universitaire de Nice, 151 Route de Saint Antoine de Ginestière, CS 23079, 06202 Nice Cedex 3, France

vanbiervliet.g@chu-nice.fr

\section{MAIN RECOMMENDATIONS}

1 ESGE recommends against diagnostic/therapeutic papillectomy when adenoma is not proven.

Strong recommendation, low quality evidence. 
2 ESGE recommends endoscopic ultrasound and abdominal magnetic resonance cholangiopancreatography (MRCP) for staging of ampullary tumors.

Strong recommendation, low quality evidence.

3 ESGE recommends endoscopic papillectomy in patients with ampullary adenoma without intraductal extension, because of good results regarding outcome (technical and clinical success, morbidity, and recurrence).

Strong recommendation, moderate quality evidence.

4 ESGE recommends en bloc resection of ampullary adenomas up to $20-30 \mathrm{~mm}$ in diameter to achieve R0 resection, for optimizing the complete resection rate, providing optimal histopathology, and reduction of the recurrence rate after endoscopic papillectomy.

Strong recommendation, low quality evidence.

5 ESGE suggests considering surgical treatment of ampullary adenomas when endoscopic resection is not feasible for technical reasons (e.g. diverticulum, size $>4 \mathrm{~cm}$ ), and in the case of intraductal involvement (of $>20 \mathrm{~mm}$ ). Surveillance thereafter is still mandatory.

Weak recommendation, low quality evidence.

6 ESGE recommends direct snare resection without submucosal injection for endoscopic papillectomy.

Strong recommendation, moderate quality evidence.

7 ESGE recommends prophylactic pancreatic duct stenting to reduce the risk of pancreatitis after endoscopic papillectomy.

Strong recommendation, moderate quality evidence.

8 ESGE recommends long-term monitoring of patients after endoscopic papillectomy or surgical ampullectomy, based on duodenoscopy with biopsies of the scar and of any abnormal area, within the first 3 months, at 6 and 12 months, and thereafter yearly for at least 5 years.

Strong recommendation, low quality evidence.

\section{SOURCE AND SCOPE}

This is the first part of a two-part guideline from the European Society of Gastrointestinal Endoscopy (ESGE) and covers the endoscopic management of ampullary tumors. The companion guideline will give guidance on superficial nonampullary tumors of the duodenum.

\section{Introduction}

Ampullary tumors are increasingly diagnosed nowadays because of better accuracy of gastroscopy and endoscopic detection technologies. Endoscopy has taken an important role in management of these lesions, particularly in a curative setting. Nevertheless, diagnostic and therapeutic strategies have to be clearly defined.

This Guideline does not discuss ampullary and duodenal lesions associated with predisposing genetic syndromes, including familial adenomatous polyposis, or lesions of submucosal and neuroendocrine origin, as they are considered in another Guideline from the European Society of Gastrointestinal Endoscopy (ESGE) [1]. While indications for endoscopic treatment and follow-up may be different between the sporadic and polyposisrelated forms, the statements regarding diagnosis, evaluation, technical modalities of endoscopic papillectomy, and management of complications are similar. Furthermore, while the majority of ampullary lesions involve the major papilla, the recommendations in this guidance should also be applied in the case of a tumor of the minor papilla in a patient with a pancreas divisum.

\begin{tabular}{|c|c|}
\hline \multicolumn{2}{|c|}{ ABBREVIATIONS } \\
\hline APC & argon plasma coagulation \\
\hline CA-EGD & cap-assisted esophagogastroduodenoscopy \\
\hline $\mathrm{Cl}$ & confidence interval \\
\hline CT & computed tomography \\
\hline EMR & endoscopic mucosal resection \\
\hline ERCP & $\begin{array}{l}\text { endoscopic retrograde cholangiopancreato- } \\
\text { graphy }\end{array}$ \\
\hline ESGE & $\begin{array}{l}\text { European Society of Gastrointestinal } \\
\text { Endoscopy }\end{array}$ \\
\hline EUS & endoscopic ultrasound \\
\hline EUS-BD & $\begin{array}{l}\text { endoscopic ultrasound-guided biliary } \\
\text { drainage }\end{array}$ \\
\hline EUS-FNA/B & $\begin{array}{l}\text { endoscopic ultrasound fine-needle } \\
\text { aspiration/biopsy }\end{array}$ \\
\hline GRADE & $\begin{array}{l}\text { Grading of Recommendations Assessment, } \\
\text { Development and Evaluation }\end{array}$ \\
\hline IDUS & intraductal ultrasound \\
\hline IHC & immunohistochemistry \\
\hline LST-p & $\begin{array}{l}\text { laterally spreading tumor involving the } \\
\text { papilla }\end{array}$ \\
\hline MRCP & $\begin{array}{l}\text { magnetic resonance cholangiopancreato- } \\
\text { graphy }\end{array}$ \\
\hline OR & odds ratio \\
\hline RCT & randomized controlled trial \\
\hline RFA & radiofrequency ablation \\
\hline SEMS & self-expandable metal stent \\
\hline
\end{tabular}

ABBREVIATIONS

Cl confidence interval

CT computed tomography

EMR endoscopic mucosal resection

ESGE $\quad$ Eraphy Endoscopy

EUS endoscopic ultrasound

drainage
EUS-FNA/B endoscopic ultrasound fine-needle

Grading of Recommendations Assessment, Development and Evaluation

IHC immunohistochemistry

LST-p laterally spreading tumor involving the papilla

MRCP magnetic resonance cholangiopancreatography

OR odds ratio

RCT randomized controlled tria

SEMS self-expandable metal stent 


\section{Methods}

ESGE commissioned this Guideline (Guideline Committee Chair, J.v.H) and appointed a Guideline leader (G.V.) who invited the listed authors to participate in the project development. The key questions were prepared by the guideline leader and then approved by the other project members. The coordinating team established task force subgroups, each with its own leader, that were assigned key questions (see Appendix 1s, online-only Supplementary Material).

Each task force performed a systematic literature search to prepare evidence-based and well-balanced statements on their assigned key questions. The literature search was performed for English-language articles in MEDLINE, Embase, and the Cochrane database, focusing on meta-analyses and fully published prospective studies, particularly randomized controlled trials (RCTs), performed in humans. Retrospective analyses and pilot studies were also included if they addressed topics not covered in the prospective studies. The Grading of Recommendations Assessment, Development, and Evaluation (GRADE) system was adopted to define the strength of recommendation and the quality of evidence. Each task force proposed statements on their assigned key questions which were discussed during a web meeting in July 2020. Literature searches were re-run in September 2020. This time-point should be the starting point in the search for new evidence for future updates to this Guideline.

In September 2020, a draft prepared by G.V. was sent to all group members for review. The draft was also reviewed by two external reviewers and then sent for further comments to the ESGE member societies and individual members. After agreement on a final version, the manuscript was submitted to the journal Endoscopy for publication. All authors agreed on the final revised version.

This Guideline was issued in 2021 and will be considered for review in 2025, or sooner if new and relevant evidence becomes available. Any updates to the Guideline in the interim period will be noted on the ESGE website: http://www.esge. com/esge-guidelines.html.

\section{Diagnosis of ampullary tumors (see $\rightarrow$ Fig. 1 )}

\subsection{Epidemiology, histology, and staging classification}

\section{RECOMMENDATION}

ESGE suggests using the latest TNM classification for staging ampullary tumors.

Weak recommendation, low quality evidence.

Neoplasia of the ampulla of Vater is a rare disease with an incidence of less than 1 per 100000 per year and representing only $0.6 \%-0.8 \%$ of the digestive cancers, with a male to female sex ratio of 1.5 [2,3]. Although the incidence of the disease amongst young adults (<45 years) has risen during the last 20 years, its trend has remained more stable in older age groups [4].
The majority of benign or malignant ampullary tumors are sporadic and involve the major papilla. Nevertheless, a genetic predisposition must be suspected in the case of diagnosis at a younger age. Familial adenomatous polyposis syndrome represents the strongest hereditary predisposition with a 120 -fold increased relative risk compared to the general population [5]. Other predisposing genetic syndromes have been described more anecdotally, such as neurofibromatosis type I (not only for somatostatinomas but also for carcinoma) or Muir-Torre syndrome [6].

The precursor lesions can arise from intestinal-type mucosa as well as from pancreatic duct-type ampullary mucosa, and these constitute the two main histological subsets [6]. The intestinal type evolves through a well-known adenoma-carcinoma sequence. The pancreaticobiliary type evolves from precursor pancreatic duct intraepithelial neoplasia. After adenoma, intraepithelial neoplasia (dysplasia and carcinoma in situ) and adenocarcinoma, more unusual histological variants are listed, including mixed-type (glandular and squamous cell components), mucinous (colloid), signet-ring cell carcinomas, neuroendocrine, and undifferentiated carcinomas [6].

Staging of the lesion must be based on the latest TNM classification [7]. Compared to the previous one, the new classification has been modified with regard to extent of the primary tumor and regional lymph node involvement ( $>$ Table 1 ). This latest classification was evaluated retrospectively in two large patient cohorts $[8,9]$. Although the $\mathrm{N}$ categories seemed to classify patients correctly, the subcategories for the $T$ stage seemed to be insufficiently precise with no significant differences in recurrence-free survival between T1b and T2 or between $\mathrm{T} 2$ and T3a.

For all stages combined, disease-specific survival at 1 and 5 years is reported to range from $71.7 \%$ to $89 \%$ and from $38.8 \%$ to $47.2 \%$, respectively $[2,10]$. This outcome is significantly better compared with carcinomas located in the duodenum, distal bile duct, and pancreatic head [10]. Tumors presented at stage 1 in up to a third of cases which was one of the most relevant independent factors predictive of survival $[2,11]$.

\subsection{Diagnostic modalities, endoscopic assessment, and prognostic value}

\section{RECOMMENDATION}

ESGE suggests using the cap-assisted method when the papilla is not seen during forward-viewing endoscopy. Weak recommendation, moderate quality evidence.

\section{RECOMMENDATION}

ESGE recommends using a side-viewing endoscope when an ampullary tumor is suspected.

Strong recommendation, moderate quality evidence.

Most noninvasive ampullary tumors of the major papilla are asymptomatic and are detected during conventional upper endoscopy performed for another indication. They can also 


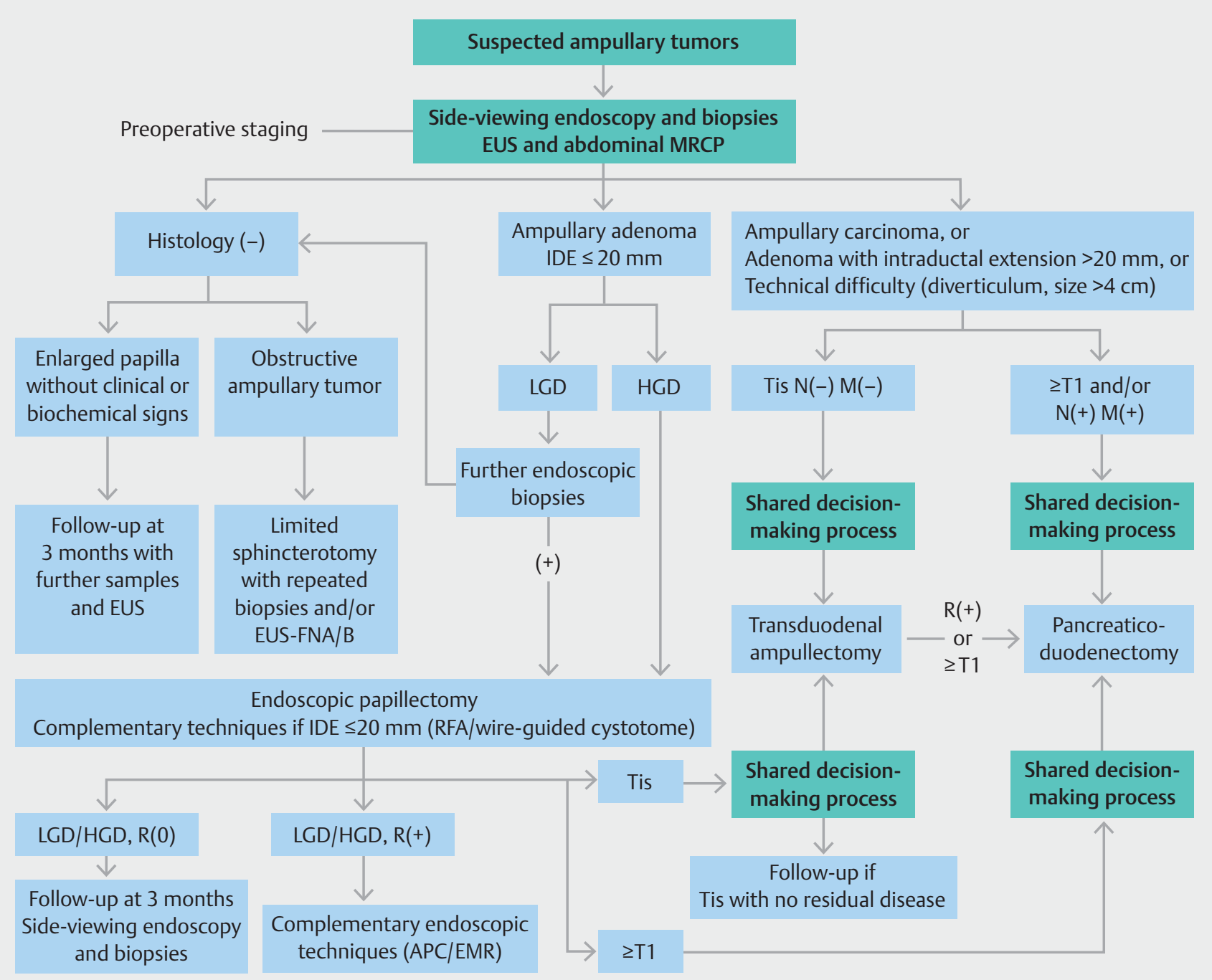

- Fig. 1 Diagnostic and therapeutic algorithm for ampullary tumor. EUS, endoscopic ultrasound; MRCP, magnetic resonance cholangiopancreatography; IDE, intraductal extension; EUS-FNA/B, endoscopic ultrasound fine needle aspiration/biopsy; LGD, low grade dysplasia; HGD, high grade dysplasia; Tis, tumor/carcinoma in situ; RFA, radiofrequency ablation; APC, argon plasma coagulation; EMR, endoscopic mucosal resection.

present with jaundice(16.6\%), pain (14.4\%), pancreatitis (4.1\%), and cholangitis (1\%) [6], and can be associated with common bile duct stones in up to $38 \%$ of cases [12]. Assessment of the lesions may demand expertise; for this reason, in the recent ESGE publication Performance measures for upper gastrointestinal endoscopy, the visualization of the papilla has been formulated as a research priority with regard to quality measures for complete high quality endoscopy [13].

Exploration of the papilla is frequently incomplete when a forward-viewing gastroscope is used because of the tangential angle involved [14, 15]. Cap-assisted esophagogastroduodenoscopy (CA-EGD) has been shown in an RCT crossover study to significantly better visualize the entire major papilla compared with standard gastroscopy ( $97 \%$ vs. $24 \%, P<0.001)$ [16]. Two recent prospective noninferiority RCTs comparing CA-EGD and side-viewing duodenoscopy had conflicting results. Abdelhafez et al. [17] found better scores for CA-EGD regarding the exam- ination of mucosal pattern and overall satisfaction but a better periampullary overview score for duodenoscopy. In the second trial the noninferiority of CA-EGD compared to duodenoscopy was not confirmed as the main papilla was completely seen in $68 \%$ versus $86 \%$ of patients, respectively [18]. Therefore capassisted EGD can be recommended when the major papilla is not seen by esophagogastroduodenoscopy (EGD) but sideviewing duodenoscopy is recommended for optimal visualization of the papilla and assessment of the feasibility of endoscopic resection.

Papillary tumors can be limited to the ampullary mound, present with an extrapapillary component in $6.9 \%-43.8 \%$ of cases, and/or have an intraductal presentation [19-24]. Laterally spreading lesions of the papilla may have an extrapapillary component and may have characteristics in common with superficial nonampullary duodenal tumors [23]. There is no validated endoscopic classification of ampullary patterns. In addi- 
- Table 1 Pathologic TNM staging of carcinomas of the ampulla of Vater [7].

Primary tumor (pT)
TX: primary tumor cannot be assessed
T0: no evidence of primary tumor
Tis: carcinoma in situ
T1: tumor limited to ampulla of Vater or sphincter of Oddi or tumor in
vades beyond the sphincter of Oddi (perisphincteric invasion) or into
the duodenal submucosa
- T1a: tumor limited to ampulla of Vater or sphincter of Oddi
- T1b: tumor invades beyond the sphincter of Oddi (perisphincteric
invasion) or into the duodenal submucosa

T2: tumor invades into the muscularis propria of the duodenum

T3: tumor directly invades into the pancreas (up to $0.5 \mathrm{~cm}$ ) or tumor extends more than $0.5 \mathrm{~cm}$ into the pancreas or extends into peripancreatic or periduodenal tissue or duodenal serosa without involvement of the celiac axis or superior mesenteric artery

- T3a: tumor directly invades the pancreas (up to $0.5 \mathrm{~cm}$ )

- T3b: tumor extends more than $0.5 \mathrm{~cm}$ into the pancreas or extends into peripancreatic tissue or periduodenal tissue or duodenal serosa without involvement of the celiac axis or superior mesenteric artery

T4: tumor involves the celiac axis, superior mesenteric artery, or common hepatic artery, irrespective of size

\begin{tabular}{|l|}
\hline Regional lymph nodes $(\mathbf{p N})$ \\
\hline NX: regional lymph nodes cannot be assessed \\
\hline N0: no regional lymph node involvement \\
\hline N1: metastasis to one to three regional lymph nodes \\
\hline N2: metastasis to four or more regional lymph nodes \\
\hline Distant metastasis (pM) \\
\hline M0: no distant metastasis \\
\hline M1: distant metastasis \\
\hline
\end{tabular}

tion, the appearance of benign small ampullary adenomas can be indistinguishable from normal papilla. Regular surface/margins, soft appearance, and mobility can be considered benign features [25]. However, ulceration, firmness, spontaneous bleeding or friability, depressed component, and nonlifting of laterally spreading lesions suggest local invasion [26].

Tumor size may guide therapy and predict endoscopic outcomes, but studies to date have conflicting results. Larger tumor sizes (mainly with a cutoff of $20 \mathrm{~mm}$ ) have been associated with malignancy $[24,27,28]$ or residual disease/recurrence in observational studies [21].

\section{RECOMMENDATION}

ESGE suggests the use of high resolution virtual chromoendoscopy for endoscopic diagnosis and staging of ampullary tumors.

Weak recommendation, low quality evidence.

Dye-based and electronic chromoendoscopy have been proposed to differentiate benign from neoplastic lesions, and also the types of neoplastic lesions. Currently, only data from magnifying narrow band imaging (NBI) have been published that use microsurface and microvessel patterns to guide endoscopic diagnosis. In the context of ampullary tumors, irregular villous arrangement and abnormal microvasculature have presented diagnostic accuracies of $73 \%$ and $90 \%$, respectively [29, 30]. The concomitant presence of the above NBI features diagnosed adenocarcinoma with sensitivity, specificity, positive predictive value, negative predictive value, and accuracy of $69 \%, 100 \%$, $100 \%, 85 \%$, and $89 \%$, respectively [30]. Indigo carmine chromoendoscopy and $\mathrm{NBI}$ appeared useful in enhancing tumor margins prior to endoscopic papillectomy [31].

\subsection{Histological diagnosis and staging of ampullary tumors}

\section{RECOMMENDATION}

ESGE recommends against diagnostic/therapeutic papillectomy when adenoma has not been proven.

Strong recommendation, low quality evidence.

\section{RECOMMENDATION}

ESGE recommends histological confirmation by endoscopic biopsies in the case of low grade dysplasia adenoma before initiating any treatment.

Strong recommendation, low quality evidence.

\section{RECOMMENDATION}

ESGE recommends follow-up with endoscopic ultrasound (EUS), side-viewing endoscopy, and further sampling with repeated biopsies for an enlarged papilla without clinical or biochemical signs in the case of initial negative histopathology.

Strong recommendation, low quality evidence.

\section{RECOMMENDATION}

ESGE suggests further investigations, at first including endoscopic ultrasound-guided fine-needle aspiration/ biopsy (EUS-FNA/B) and then limited sphincterotomy with repeated biopsies, when an obstructive ampullary tumor is suspected that has initial negative histopathology. Strong recommendation, low quality evidence. 
Endoscopic biopsy and histological examination with routine hematoxylin and eosin-stained sections is regarded as mandatory in the diagnosis of ampullary tumors. Nevertheless, the diagnostic accuracy of preprocedural biopsy has been reported to range from $38.3 \%$ to $85 \%$ [12,32-37] which is insufficient to determine appropriate treatment modalities ( $\triangleright$ Table 2 ). The rate of histological underestimation can reach $30 \%[19,32,37$, $39,40]$. The rate of diagnostic overestimation, leading to potentially inadequate and risky treatment, has been prospectively evaluated to be $15 \%$ overall, and $21 \%$ for initial low grade dysplasia diagnosis [19]. Normal intestinal mucosa or inflammatory tissue were found in post-papillectomy histological analysis in $8 \%$ and in $13.8 \%$ in two large retrospective series $[37,41]$.

The options to confirm the diagnosis will then depend on clinical (pain, jaundice), biological (cholestasis, pancreatitis), or endoscopically suspicious features. They comprise close follow-up, further sampling, sphincterotomy and further biopsies, EUS-guided tissue acquisition, or papillectomy with a full en bloc pathological specimen. This should be accompanied by close follow-up and further sampling in asymptomatic patients with an enlarged "pseudovillous papilla" as the safety profile of endoscopic biopsies is excellent and repeated histological examination provides a $14 \%$ improvement in diagnosis $[35,42]$. In the case of a bulging papilla without abnormality, several reports have suggested that endoscopic biopsies should be done after an endoscopic sphincterotomy. However, conflicting results have been published, with reported low sensitivities of between $21 \%$ and $37 \%$ as post-sphincterotomy changes may produce cytoarchitectural atypia $[34,43,44]$. As a result, a reduction of the diagnostic accuracy was described in patients who benefited from sphincterotomy before sampling $(56.25 \%$ vs. $81.25 \%$ ) [33]. Taking further samplings at least 10 days after sphincterotomy can be useful to avoid initial false-negative results [45].

Although only a few reports have described EUS-FNA for tumors of the ampulla of Vater, EUS-FNA might be another option when an invasive adenocarcinoma is suspected at EUS $[46,47]$. Performance seems to be safe and accurate, with a sensitivity of $82.4 \%$, a specificity of $100 \%$, and an accuracy of $88.8 \%$ [46]. If considered, it should be performed before sphincterotomy [47].

Finally, if the diagnosis of a neoplastic benign lesion is proven by histology and suspected malignancy cannot be confirmed by biopsy and/or EUS-FNA, endoscopic papillectomy can be considered as an appropriate diagnostic-therapeutic step if the resection seems feasible and safe [48].

- Table 2 Accuracy of endoscopic biopsy in preoperative diagnosis of ampullary tumors.

\begin{tabular}{|c|c|c|c|}
\hline First author, year & $\begin{array}{l}\text { Participants, } n \text {, } \\
\text { Study design }\end{array}$ & $\begin{array}{l}\text { Overall accuracy of endoscopic } \\
\text { biopsy, \% }\end{array}$ & Discordance with final results \\
\hline Kimchi, 1998 [12] & $\begin{array}{l}28, \\
\text { Retrospective }\end{array}$ & 85 & - \\
\hline Yamaguchi, 1990 [32] & $\begin{array}{l}78, \\
\text { Retrospective }\end{array}$ & 70 & $\begin{array}{l}\text { Underestimation } 28 \% \\
\text { Overestimation } 1.3 \%\end{array}$ \\
\hline Rodriguez, 2002 [33] & $\begin{array}{l}32, \\
\text { Retrospective }\end{array}$ & 68.7 & - \\
\hline Menzel, 1999 [34] & $\begin{array}{l}40, \\
\text { Retrospective }\end{array}$ & 63 & - \\
\hline Elek, 2003 [35] & $\begin{array}{l}226, \\
\text { Retrospective }\end{array}$ & 69 & - \\
\hline Grobmyer, 2008 [36] & $\begin{array}{l}29, \\
\text { Retrospective }\end{array}$ & 76 & - \\
\hline Laleman, 2013 [37] & $\begin{array}{l}91, \\
\text { Retrospective }\end{array}$ & 38.3 & $\begin{array}{l}\text { Underestimation } 31.9 \% \\
\text { Overestimation } 29.8 \%\end{array}$ \\
\hline Yamamoto, 2019 [38] & $\begin{array}{l}177, \\
\text { Retrospective }\end{array}$ & 81.9 & $\begin{array}{l}\text { Underestimation } 14.1 \% \\
\text { Overestimation } 3.9 \%\end{array}$ \\
\hline Napoleon, 2014 [19] & $\begin{array}{l}93, \\
\text { Prospective }\end{array}$ & 67 & $\begin{array}{l}\text { Underestimation } 23 \% \\
\text { Overestimation } 15 \%\end{array}$ \\
\hline Li, 2019 [39] & $\begin{array}{l}110, \\
\text { Retrospective }\end{array}$ & 68.2 & $\begin{array}{l}\text { Underestimation } 30.9 \% \\
\text { Overestimation } 0.9 \%\end{array}$ \\
\hline Kim, 2013 [40] & $\begin{array}{l}\text { 91, } \\
\text { Retrospective }\end{array}$ & 53.8 & $\begin{array}{l}\text { Underestimation } 26.4 \% \\
\text { Overestimation } 6.5 \%\end{array}$ \\
\hline
\end{tabular}




\section{RECOMMENDATION}

ESGE suggests that, currently, immunohistochemistry (IHC), K-ras and p53 evaluation, polymerase chain reaction, and microsatellite instability testing should not routinely be applied to ampullary tumor biopsies to inform prognosis and/or potential response to treatment. Weak recommendation, low quality evidence.

IHC is not routinely applied in all ampullary biopsies. The dichotomous classification into intestinal or pancreaticobiliary phenotypes is of significant prognostic value, and IHC panels including MUC1, MUC2, CDX2, CK20 and MUC5AC can be used in resected specimens to aid subtyping $[49,50]$. For endoscopic biopsies, however, morphological and IHC classifications into intestinal or pancreaticobiliary phenotypes are inconsistent, owing to tissue heterogeneity and antigenicity, interpretation of staining patterns, and inter-/intraobserver variability. IHC is used to confirm the diagnosis of carcinoma in poorly differentiated/undifferentiated tumors and to distinguish those from nonepithelial malignancies [51]. K-ras and p53 have been found to be mutated in different histological subtypes of ampullary adenocarcinoma and do not allow definitive histological subtyping of intestinal and pancreaticobiliary phenotypes emphasizing the common occurrence of hybrid phenotypes. Wntsignaling and microsatellite instability testing may become important for informing treatment approaches in the future [52]. Molecular profiling was not found to add significant value to clinicopathological variables in resected specimens [53].

\section{RECOMMENDATION}

ESGE recommends endoscopic ultrasound (EUS) and abdominal magnetic resonance cholangiopancreatography (MRCP) for staging of ampullary tumors.

Strong recommendation, low quality evidence.

\section{RECOMMENDATION}

ESGE suggests that intraductal ultrasound (IDUS) can be useful in selected patients with ampullary tumors; however, routine use must be balanced against training, costs, and risk of pancreatitis.

Weak recommendation, low quality evidence.

Transabdominal ultrasound, computed tomography (CT), MRCP, EUS, duodenoscopy, and endoscopic retrograde cholangiopancreatography (ERCP) with intraductal ultrasound (IDUS) have all been used for detection and staging of ampullary tumors [54-72].

The performance of EUS was evaluated in a meta-analysis that included 422 patients from 14 studies [70]. The pooled sensitivity and specificity of EUS were $77 \%$ (95\%Cl 69\%-83\%) and $78 \%$
(95\% Cl 72\%-84\%), respectively, for T1 tumors. The pooled sensitivity and specificity of morphological criteria for lymph node involvement were $70 \%(95 \% \mathrm{Cl} 62 \%-77 \%)$ and $74 \%$ (95\% Cl 67\%-80\%), respectively. An overall moderate strength of agreement with histopathology in preoperative staging was concluded, but EUS has been shown to have higher detection accuracy for ampullary tumors in comparative studies. EUS provides significantly higher performance especially for T staging compared with CT and transabdominal ultrasound, and comparable or slightly but not significantly higher accuracy compared with MRCP $[54,55,62,64-68]$. For N staging, MRCP had the best performance, but the difference was not significant as compared to EUS and CT $[60,66,68,71]$. The sensitivity of EUS for malignant lymph node diagnosis was statistically superior to that of CT [72]. Finally, EUS and MRCP appear to be reproducible and safe techniques for determining the presence of a pancreas divisum which modifies the endoscopic papillectomy technique for tumors of the major papilla [73].

IDUS for T-staging in ampullary tumors has been reported to have overall accuracies between $78 \%$ and $90.2 \%[34,60,71$, 74-76]. Ito et al., in a prospective study of 40 patients who underwent IDUS before surgery $(n=30)$ or endoscopic papillectomy $(n=10)$, reported an accuracy in T-staging of $78 \%$ overall and of $100 \%$ for those who underwent endoscopic papillectomy [74]. Ductal infiltration was correctly assessed in $90 \%$ of cases in both biliary and pancreatic ducts. In another retrospective study including 72 patients with suspected ampullary tumors, IDUS had sensitivity, specificity, and accuracy for the diagnosis of ampullary carcinoma of $87.5 \%, 92.5 \%$ and $90.2 \%$, respectively [75]. Most reports suggest that IDUS has diagnostic yields that are slightly higher than or comparable to those of EUS $[34,77]$, and should be combined with other diagnostic modalities such as forceps biopsy [77]. In addition, IDUS could also be useful to guide direct tissue acquisition by biopsy or brush cytology. However, there is a risk of post-ERCP pancreatitis and the specific morphological criteria predicting malignancy in these patients are unclear.

\section{Treatment of ampullary tumors (see $\rightarrow$ Fig. 1)}

\subsection{Endoscopic and surgical approaches}

\section{RECOMMENDATION}

ESGE recommends endoscopic papillectomy in patients with ampullary adenoma without intraductal extension, because of good results regarding outcomes (technical and clinical success, morbidity, and recurrence).

Strong recommendation, moderate quality evidence. 


\section{RECOMMENDATION}

ESGE recommends en bloc resection of ampullary adenomas up to $20-30 \mathrm{~mm}$ in diameter to achieve R0 resection, for optimizing the complete resection rate, providing optimal histopathology, and reduction of the recurrence rate after endoscopic papillectomy.

Strong recommendation, low quality evidence.

\section{RECOMMENDATION}

ESGE suggests considering surgical treatment of ampullary adenomas when endoscopic resection is not feasible for technical reasons (e.g. diverticulum, size $>4 \mathrm{~cm}$ ), and in the case of intraductal involvement (of $>20 \mathrm{~mm}$ ). Surveillance thereafter is still mandatory.

Weak recommendation, low quality evidence.

The initial case series that reported the outcomes of endoscopic papillectomy were quite small and included favorable outcomes in benign lesions and lesions without intraductal growth [25, 78-81]. The results of subsequent studies included patients with adenocarcinoma (initially diagnosed with ampullary adenoma on preprocedural work-up but with adenocarcinoma revealed in post-procedural histology) with an adverse event rate similar to that in previous studies [21, 37, 82-87].

Based on these studies, a systematic review with pooled analysis was published in 2020 by Spadaccini et al., that included 29 studies reporting the results of endoscopic papillectomy in a total of 1751 patients [26]. The overall adverse event rate was $24.9 \%\left(95 \% \mathrm{Cl} 21.2 \%-29.0 \%\right.$; $\left.I^{2}=66 \%\right)$. The most common adverse events reported after endoscopic papillectomy were post-procedural pancreatitis in $11.9 \%\left(95 \% \mathrm{Cl} 10.4-13.6 ; R^{2}=\right.$ $41 \%)$, followed by bleeding in $10.6 \%\left(95 \% \mathrm{Cl} 5.2-13.6 ; R^{2}=\right.$ $61 \%)$. Perforations and cholangitis were reported in $3.1 \%$ $\left(95 \% \mathrm{Cl} 2.2-4.2 ; R^{2}=17 \%\right)$ and $2.7 \%\left(95 \% \mathrm{Cl} 1.9-4.0 ; R^{2}=32 \%\right)$, respectively. The long-term adverse effect of papillary stenosis occurred in $2.4 \%\left(95 \% \mathrm{Cl} 1.6-3.4 ; R^{2}=0\right)$. Mortality was $0.3 \%$. Complete endoscopic resection (technical success defined as the absence of any adenomatous remnant from the resection margins at the end of the procedure) was achieved in $94.2 \%$ (95\% Cl 90.5-96.5; $I^{2}=73 \%$ ), and curative endoscopic resection (oncologic success defined as the absence of any histological features which predict locoregional persistence) in $87.1 \%$ (95\% Cl 83.0-90.3; $\left.R^{2}=70 \%\right)$. En bloc resection was achieved in $82.4 \%\left(95 \% \mathrm{Cl} 74.7-88.1 ; I^{2}=84 \%\right)$, and this was the only factor affecting curative resection (odds ratio [OR] 3.55, 95\% Cl 1.115.99, $P=0.004)$. In one of the largest retrospective series on endoscopic papillectomy, en bloc resection was significantly associated with a higher complete resection rate compared to piecemeal resection ( $O R 4.05,95 \% \mathrm{Cl} 1.71-9.59, P<0.001$ ) [85]. A summary of the more recently published results is provided in $>$ Table 3 .

No well-designed, prospective studies comparing endoscopic papillectomy and surgical treatment (transduodenal ampullectomy or pancreaticoduodenectomy) of ampullary tumors are available. As endoscopic papillectomy is increasingly performed, surgical excision seems to be used less frequently. However, surgical transduodenal ampullectomy is still an acceptable option for ampullary adenoma, being preferred to

- Table 3 Outcomes of endoscopic papillectomy: summary of recently published results.

\begin{tabular}{|c|c|c|c|c|c|}
\hline \multirow[t]{2}{*}{ First author, year } & \multirow{2}{*}{$\begin{array}{l}\text { Participants, n, } \\
\text { Study design }\end{array}$} & \multicolumn{4}{|l|}{ Outcomes, n/n (\%) } \\
\hline & & En bloc resection & Clinical success* & Overall morbidity & Recurrence \\
\hline Spadaccini, 2020 [26] & $\begin{array}{l}1751, \\
\text { Systematic review }\end{array}$ & $\begin{array}{l}763 / 926 \\
(82.4 \%)\end{array}$ & $\begin{array}{l}1384 / 1589 \\
(87.1 \%)\end{array}$ & $\begin{array}{l}407 / 1751 \\
(24.9 \%)\end{array}$ & $\begin{array}{l}157 / 1331 \\
(11.8 \%)\end{array}$ \\
\hline Li, 2019 [39] & $\begin{array}{l}110, \\
\text { Retrospective cohort }\end{array}$ & $\begin{array}{l}83 / 110 \\
(75.5 \%)\end{array}$ & $\begin{array}{l}86 / 110 \\
(78.2 \%)\end{array}$ & $\begin{array}{l}39 / 110 \\
(35 \%)\end{array}$ & $\begin{array}{l}13 / 110 \\
(11.8 \%)\end{array}$ \\
\hline Yamamoto, 2019 [38] & $\begin{array}{l}177, \\
\text { Retrospective cohort }\end{array}$ & - & - & $\begin{array}{l}76 / 177 \\
(42.9 \%)\end{array}$ & $0 \%$ \\
\hline Sahar, 2020 [88] & $\begin{array}{l}161, \\
\text { Retrospective cohort }\end{array}$ & $\begin{array}{l}115 / 161 \\
(72 \%)\end{array}$ & $\begin{array}{l}106 / 128 \\
(83 \%)\end{array}$ & $\begin{array}{l}24 / 161 \\
(14.9 \%)\end{array}$ & $\begin{array}{l}12 / 161 \\
(7 \%)\end{array}$ \\
\hline Tringali, 2020 [89] & $\begin{array}{l}135, \\
\text { Retrospective cohort }\end{array}$ & $\begin{array}{l}112 / 135 \\
(83 \%)\end{array}$ & $\begin{array}{l}96 / 103 \\
(93 \%)\end{array}$ & $\begin{array}{l}29 / 135 \\
(21.5 \%)\end{array}$ & $\begin{array}{l}24 / 103 \\
(23 \%)\end{array}$ \\
\hline van der Wiel, 2019 [20] & $\begin{array}{l}87, \\
\text { Retrospective cohort }\end{array}$ & $\begin{array}{l}41 / 87 \\
(47.1 \%)\end{array}$ & $\begin{array}{l}67 / 87 \\
(77 \%)\end{array}$ & $\begin{array}{l}23 / 87 \\
(26.4 \%)\end{array}$ & $\begin{array}{l}10 / 87 \\
(11.5 \%)\end{array}$ \\
\hline Lee, 2020 [90] & $\begin{array}{l}53, \\
\text { Retrospective cohort }\end{array}$ & $\begin{array}{l}30 / 53 \\
(56.6 \%)\end{array}$ & $\begin{array}{l}41 / 45 \\
(91.1 \%)\end{array}$ & $\begin{array}{l}10 / 53 \\
(18.9 \%)\end{array}$ & $\begin{array}{l}16 / 53 \\
(32.7 \%)\end{array}$ \\
\hline Total & & $\begin{array}{l}1144 / 1472 \\
(77.7 \%)\end{array}$ & $\begin{array}{l}1780 / 2062 \\
(86.3 \%)\end{array}$ & $\begin{array}{l}608 / 2474 \\
(24.6 \%)\end{array}$ & $\begin{array}{l}232 / 1845 \\
(12.6 \%)\end{array}$ \\
\hline
\end{tabular}


endoscopic papillectomy in the following settings: intraductal involvement; impossibility of performing endoscopic papillectomy for technical reasons (e.g. diverticulum, size $>4 \mathrm{~cm}$ ); incomplete resection after endoscopic papillectomy with positive margins; and local recurrence not treatable by endoscopy $[91,92]$. A comparative systematic review including 5 studies on ampullary tumors showed that surgical resection (transduodenal ampullectomy or pancreaticoduodenectomy) had more favorable results in terms of complete cure of adenoma compared to endoscopic papillectomy (risk difference [RD] -0.37 , $95 \% \mathrm{Cl}-0.50$ to $-0.24, P<0.001, P^{2}=71 \%$ ) and showed no differences in terms of complications [93]. Nevertheless, in the fixedeffects model, endoscopic papillectomy showed a lower rate of adverse events (RD $-0.28,95 \% \mathrm{Cl}-0.39$ to $-0.18, P<0.001 ; P^{2}=$ $95 \%)$. Two additional retrospective comparative studies, not included in the abovementioned meta-analysis, that involved a total of 139 patients with suspected benign ampullary tumors who underwent endoscopic papillectomy and transduodenal ampullectomy, confirmed a higher morbidity in the surgical groups compared to the endoscopic papillectomy groups (Ceppa et al. [94], 109 patients, $42 \%$ vs. $18 \%, P=0.006$; Dubois et al. [95], 30 patients, $68 \%$ vs. $9 \%, P=0.002$ ). Finally, a third study, including 66 patients with benign and malignant ampullary tumors ( $\leq \mathrm{T} 1$ ) treated by local resection either by endoscopic papillectomy or transduodenal ampullectomy, revealed higher rates of adverse events ( $10 \%$ vs. $35 \%$ ) but lower $\mathrm{R} 1$ resection rates $(30 \%$ vs. $0 \%$ ) for transduodenal ampullectomy [91]. Nevertheless, in most of these retrospective series, more advanced disease was noted in the patients treated by surgery, thus interpretation of their findings must be uncertain. A series from Sauvanet et al. [96] even showed the possibility of complete excision of ampullary tumors with intraductal growth (25-70 mm), by combining transduodenal ampullectomy with complete common bile duct excision in 7 patients.

It is important to underline that for both endoscopic papillectomy and transduodenal ampullectomy, operator and center experience are crucial to ensure good outcomes and low morbidity rates [91].

If en bloc endoscopic resection could be technically feasible for tumors up to $3 \mathrm{~cm}$, and surgical treatment is indicated for tumors $>4 \mathrm{~cm}$, the management of patients with ampullary tumors sized between 3 and $4 \mathrm{~cm}$ should be considered on a caseby-case basis.

\section{RECOMMENDATION}

ESGE recommends that a laterally spreading tumor involving the papilla (LST-p) can be managed by endoscopic resection, but the higher risk of intraprocedural and delayed bleeding should be taken into consideration. Strong recommendation, low quality evidence.

A laterally spreading tumor involving the papilla Vateri (LST-p) is defined as a laterally spreading ampullary tumor with $a \geq 10-\mathrm{mm}$ extension beyond the ampullary mound [23] or with an extrapapillary component, involving the duodenal wall, that is greater than the size of the papillary adenoma [88]. Endoscopic treatment of LST-p showed comparable outcomes regarding endoscopic curative resection and recurrence rate to those for adenoma confined to the ampulla, in four retrospective cohorts including a total of 509 patients and 110 LST-p [20, 23, 88, 97]. In the study from Klein et al. [23] a higher risk of intraprocedural bleeding was reported (50\% vs. $24.7 \%, P$ $=0.003)$ as well as delayed bleeding ( $25 \%$ vs. $12.3 \%, P=0.08)$ with LST-p. Similar results were obtained by Sahar et al. [88] for the adverse event of delayed bleeding (14\% vs. $4 \%, P=$ $0.02)$. Nevertheless, before generalizing these results, it should be underlined that data are still limited and coming from referral centers only.

\section{RECOMMENDATION}

ESGE recommends pancreaticoduodenectomy (including lymphadenectomy) for malignant lesions of the ampulla of stage $\mathrm{T} 1$ or higher. This recommendation also applies if pathology results following an endoscopic papillectomy or surgical transduodenal ampullectomy reveal ampullary $\mathrm{T} 1$ adenocarcinoma.

Strong recommendation, low quality evidence.

\section{RECOMMENDATION}

ESGE recommends for Tis ampullary cancer that transduodenal ampullectomy or endoscopic papillectomy might be considered to be sufficient when final pathology results show no residual disease.

Strong recommendation, low quality evidence.

There are no RCTs to compare the different surgical options for ampullary carcinoma. Most series from the literature are retrospective. The standard procedure for ampullary cancer is pancreaticoduodenectomy, which is associated with postoperative morbidity of $34 \%-59 \%$ and mortality of $1 \%-2 \%$, with 5 -year survival rates after resection varying between $40 \%$ and $60 \%$. The most important prognostic factors for survival are $\mathrm{T}$ and $\mathrm{N}$ status $[27,98,99]$.

Some authors advocate for less invasive procedures for early-stage adenocarcinomas. It is important to distinguish Tis from T1 adenocarcinoma [27]. Tis carcinomas are mucosal tumors not invading the lamina propria and muscularis mucosae, which do not seem to show lymphatic invasion or lymph node involvement $[94,100,101]$.

In recent years several observational studies have been published that report potentially oncologically safe results in cases of endoscopic papillectomy performed on well-differentiated intramucosal adenocarcinoma (T1a/Du0) with no lymphatic, vascular, or perineural invasion, and without lymph node involvement [19, 38, 39, 102-105].

For Tis ampullary lesions, local transduodenal ampullectomy shows lower morbidity rates than pancreaticoduodenectomy 
and no risk for recurrence $[100,101,106,107]$. Published longterm outcomes are scarce but one study by Gao et al. [106] showed 5-year survival rates following transduodenal ampullectomy of $100 \%$ for 4 patients with Tis lesions and $72.2 \%$ for 18 patients with $T 1$ adenocarcinoma $(P=0.928)$.

On the other hand, a significant percentage of $\mathrm{T} 1$ ampullary carcinomas have lymph node metastasis, with rates varying from $9 \%$ to $45 \%[27,98,100,107,108]$. Consequently, there is a risk of incomplete resection when transduodenal ampullectomy is performed for T1 adenocarcinoma [109]. During transduodenal ampullectomy, the ampullary tumor is resected by dissection through the mucosal plane; the action is pushed as far as possible along the ducts to obtain an R0 resection [91]. It is recommended to perform appropriate frozen-section pathological examination during or after transduodenal ampullectomy. If the results do not fulfill the potential local resection criteria, the operation should be converted to pancreaticoduodenectomy [106]. Consequently, pancreaticoduodenectomy with lymphadenectomy is still the procedure of choice for $\mathrm{T} 1$ adenocarcinoma.

\subsection{Preoperative and palliative biliary drainage for ampullary tumors}

\section{RECOMMENDATION}

ESGE recommends ERCP with self-expandable metal stent (SEMS) insertion in patients with ampullary tumors and biliary obstruction in palliative settings.

Strong recommendation, high quality evidence.

An ESGE Guideline, updated in 2017, recommends treatment of malignant extrahepatic biliary obstruction by means of stenting rather than by surgery [110]. No additional high quality evidence has been published since 2017.

ERCP-guided biliary drainage is preferred over the percutaneous transhepatic route because of fewer adverse events, shorter hospital stay, lower costs, and lack of external drainage catheters, based on an analysis of a national database [111]. Since that study, a meta-analysis has been published that included all types of biliary tract/gallbladder cancer, in both resectable and unresectable settings [112]. This has shown that ERCP-guided biliary drainage and percutaneous transhepatic access have similar rates for success and overall adverse events, but that the type of adverse event differs. It was concluded that the approach should be chosen on the basis of tumor location and purpose of drainage [112]. For palliative drainage in patients with ampullary tumors, ESGE recommends ERCPguided biliary drainage as the preferred route [110].

Several meta-analyses have shown endoscopic ultrasoundguided biliary drainage (EUS-BD) to be a safe and effective option after failed ERCP-guided biliary drainage [113-115]. Recently, the choice between EUS-BD versus ERCP-guided biliary drainage as the primary modality in malignant bile duct obstruction has been analyzed in eight meta-analyses [116-123]. Technical success (around 92\%-97\%) and clinical success (around 85\%-96\%) were high for both EUS- and ERCP-guided biliary drainage, and did not differ between approaches. Total adverse events rates were similar, but EUS-BD showed lower rates of post-procedural pancreatitis. The meta-analyses reported stent dysfunction, tumor ingrowth, and re-interventions to be similar between approaches or in favor of EUS-BD. These data are promising, but the series are small and it is difficult to generalize from the data because the trials were performed in high-volume expert-center settings. In selected cases (e. g. difficult anatomy), EUS-BD might be considered as the primary approach in expert centers.

The 2017 ESGE Guideline recommends SEMSs in preference to plastic stents for endoscopic biliary drainage of malignant obstruction [110]. Since the Guideline's publication, this has been further supported by the single RCT and single metaanalysis that have been published [124, 125].

Whether a covered or uncovered SEMS should be used remains debatable. Since the 2017 ESGE Guideline, one metaanalysis [126] and two RCTs [127, 128] have been published on this topic. Tringali et al. included 11 RCTs in their meta-analysis and showed a nonsignificant risk reduction for stent failure of about $32 \%$ in favor of covered over uncovered SEMS, with no difference in adverse events [126]. Stent migration, tumor overgrowth, and sludge formation occurred more frequently in covered SEMS, but tumor ingrowth was less common. In contrast, a recent RCT published since the above meta-analysis, showed significantly better patency rates in favor of uncovered SEMS [127], and a second (studying uncovered vs. covered SEMSs with percutaneous transhepatic route after failed ERCP, and therefore a somewhat different patient population) found no difference [128]. In conclusion, from the current literature, based on studies including patients with all causes of malignant biliary obstruction (the majority with pancreatic cancer and only a minority with ampullary tumors), there is no convincing evidence for the preferential use of covered or uncovered SEMSS.

\section{RECOMMENDATION}

ESGE recommends against routine preoperative biliary drainage in patients with ampullary cancer who are eligible for surgery; preoperative biliary drainage should be reserved for patients with cholangitis, severe symptomatic jaundice (e.g, intense pruritus), or delayed surgery, or for before neoadjuvant chemotherapy in jaundiced patients.

Strong recommendation, moderate quality evidence.

\section{RECOMMENDATION}

In cases where preoperative biliary drainage is required, ESGE recommends endoscopic biliary drainage with endoscopic SEMS insertion.

Strong recommendation, moderate quality evidence. 
The 2017 ESGE Guideline recommends against routine preoperative biliary drainage in patients with malignant extrahepatic biliary obstruction [110]; A recent systematic review, published after that Guideline and including 32 studies, confirmed that refraining from preoperative drainage before pancreaticoduodenectomy may be the best management for jaundice in patients with resectable pancreatic head cancer [129]. If we focus on studies including only patients with resectable adenocarcinoma, a retrospective series including 64 patients concluded that preoperative drainage was an independent negative predictive factor influencing survival (drainage vs. no drainage, 25.3 months vs. 112.9 months, $P<0.001$ ) [130]. Similarly, a French retrospective series including 135 patients with nonductal periampullary tumors identified preoperative drainage as a predictive factor for recurrence [131]. Finally, similar results were reported by a very large Asian study ( $n=899)$ [132].

If preoperative drainage is necessary, the same ESGE Guideline recommends the endoscopic over the percutaneous transhepatic route, based on long-term follow-up showing longer patient survival and less frequent peritoneal/liver recurrence in the endoscopic groups [133-135]. An additional recent metaanalysis confirmed a lower risk of seeding with endoscopic compared to percutaneous drainage [136]. Furthermore, if preoperative drainage is required, the use of a SEMS is favored over a plastic stent, based on the results of two meta-analyses. These concluded that SEMSs were associated with lower rates of endoscopic re-intervention and perioperative cholangitis, despite potentially higher risk of preoperative biliary drainagerelated pancreatitis due to SEMS $[137,138]$.

Finally, EUS-BD has been proposed as an alternative approach in the case of failed ERCP [115] and even as a first-line approach [116]. Nevertheless, the majority of patients included in these trials underwent palliative drainage, without subsequent surgical resection. Therefore, the place of preoperative EUS-BD is still unclear, as well as the possible consequences for the outcome of the surgical procedure.

\subsection{Treatment of intraductal extension}

\section{RECOMMENDATION}

ESGE suggests the use, in expert centers, of complementary techniques (thermal ablation by cystotome, or radiofrequency ablation [RFA]) with temporary biliary stenting, for ampullary adenoma with $\leq 20$-mm intraductal extension.

Weak recommendation, low quality evidence.

Patients with ampullary adenomas and extensive intraductal involvement are usually referred for surgical therapy. Several studies have been published that report unfavorable outcomes for endoscopic treatment (curative endoscopic resection achieved in $0-9 \%$, depending on the study) $[20,85,86,139]$. Bohnacker et al. [140] reported a lower rate of endoscopic curative resection ( $46 \%$ vs. $83 \%, P<0.001)$ and a higher rate of rescue surgery ( $37 \%$ vs. $12 \%$ ) in cases of intraductal growth.
Nevertheless, two endoscopic complementary destruction techniques are available and have recently been evaluated. Pérez-Cuadrado-Robles et al. [24] proposed the use of endoscopic thermal ablation by a wire-guided cystotome combined with endoscopic papillectomy (73 patients overall including 18 with $\leq 20-\mathrm{mm}$ intraductal extension). No difference in curative resection rates was observed after a mean follow-up of 20 months ( $100 \%$ for patients with intraductal extension vs. $80.3 \%$ for those without; $P=0.093$ ).

Two retrospective studies including 4 and 13 patients with intraductal growth in the common bile duct revealed successful treatment using RFA in $75 \%$ and $92.3 \%$, respectively, in $1-5$ sessions [141, 142]. A recent RCT, including 20 patients with histologically proven endobiliary adenoma remnant (ductal extent $<20 \mathrm{~mm}$ ) after endoscopic papillectomy for ampullary adenoma, concluded that intraductal RFA can lead to a $70 \%$ dysplasia eradication at 12 months after a single session [143]. More severe histopathological level (high grade dysplasia) was a predictive factor for poor outcome requiring rescue surgery in 2 patients (10\%) [143]. Biliary stricture, requiring temporary biliary stenting, is common after RFA for intraductal extension (7/33, i.e., $21.2 \%$ of patients in the last two retrospective series) $[142,143]$.

\section{Technical considerations in endoscopic papillectomy}

\section{RECOMMENDATION}

ESGE recommends direct snare resection without submucosal injection for endoscopic papillectomy.

Strong recommendation, moderate quality evidence.

Some authors have recommended submucosal injection of ampullary tumors prior to resection, for the diagnostic purpose of facilitating the delineation of the lateral extent of the lesion and, if the nonlifting sign is present, as an indicator of a deep invasive lesion that is not amenable to endoscopic resection [144]. The prevention of bleeding and of deep thermal injury to the ducts and muscle layer are also invoked as reasons for submucosal injection [145]. Other authors do not perform injection: first because the center of the ampullary lesion is tethered down by the biliary and pancreatic ducts, and it may not lift; secondly, injection may create a "dome" effect and make effective snare placement for en bloc resection more difficult; and thirdly, there are reports of increased risk of post-resection pancreatitis.

Currently few clinical data exist to support or refute the abovementioned statements [19, 25, 79, 80, 85, 86, 145-154]. In a survey answered by 46 expert biliary endoscopists in the USA and Canada, only $12 \%$ responded that they always utilized submucosal injection in combination with endoscopic papillectomy in order to "decrease the depth of thermal injury to the duodenal wall” [155]. Only one RCT has compared endoscopic papillectomy with or without submucosal injection; it included 50 patients with biopsy-proven adenomas (26 snare- 
only, 24 injection plus snare) [156]. The complete resection rate was significantly higher in the no-injection compared to the with-injection group (80.8\% [21/26] and 50.0\% [12/24], respectively; $P=0.02)$. There was no difference in terms of complications, residual tumor at 1 month and recurrence rates at 12 months. In a retrospective study with propensity-score matching (25 paired patients), residual tumor was found more often when submucosal injection was used compared with the simple snare technique only [157]. In conclusion, the use of submucosal injection does not seem to bring any advantage.

\section{RECOMMENDATION}

ESGE suggests to avoid any biliary, pancreatic, or biductal sphincterotomy prior to endoscopic papillectomy.

Weak recommendation, very low quality evidence.

Despite the lack of clear evidence from comparative trials, many authors recommend obtaining a cholangiogram and pancreatogram prior to endoscopic papillectomy, to rule out deep intraductal extension of more than $10 \mathrm{~mm}$. However, limited data exist as to whether prior biductal sphincterotomy has an impact on the post-resection cannulation rate, pancreatic stent placement, and the outcomes of the subsequent papillectomy $[21,25,79,80,85,86,145-153]$. In one retrospective study [145], technical and clinical success rates after routine use of biductal sphincterotomy prior to resection were reported to be comparable to other larger trials using the standard technique, with a low adverse event rate of $8 \%[19,21,79,80,85,86,145$, $148,151,153]$. Remarkably the number of en bloc and singlesession resections seems to be lower, in particular when sphincterotomy is combined with pancreatic stent placement prior to resection, necessitating more treatment sessions and additional ablative techniques, such as argon plasma coagulation (APC), to achieve local complete remission [145]. Furthermore, some authors report difficulties in obtaining complete histopathological evaluation of the resected specimen because of the thermal injury following sphincterotomy $[149,158]$. One author group reported increased risk of adverse events (perforation, bleeding, and tumor cell seeding) [158].

\section{RECOMMENDATION}

ESGE recommends performing submucosal injection prior to resection of laterally spreading duodenal ampullary tumors to allow safe and effective endoscopic mucosal resection (EMR), in line with the resection technique for epithelial nonampullary duodenal lesions.

Strong recommendation, moderate quality evidence.

When there is extrapapillary extension of the adenoma to the adjacent duodenal wall, submucosal injection to that region is recommended, in line with the recommendations for EMRs in the gastrointestinal tract $[23,146,147,149,159-167]$. Submu- cosal injection separates the mucosa from the muscularis propria layer, and creates a safe plane for endoscopic resection.

\section{RECOMMENDATION}

ESGE suggests the use of endocut current for endoscopic papillectomy, to reduce intraprocedural and early postprocedural bleeding.

Weak recommendation, low quality evidence.

Currently there is no consensus regarding the optimal current and power output for endoscopic papillectomy. Some authors advocate the use of pure cutting current to avoid edema caused by the coagulation mode $[25,148]$, although a pure cutting current has been reported to be associated with bleeding. Others prefer using a blended electrosurgical current [80, $86]$ or alternating cut/coagulation modes [21,158]. A systematic review of non-RCTs did not demonstrate superiority of one modality over the other [168]. In a retrospective case-control trial focusing on adverse events with respect to technical modifications of papillectomy, the use of endocut instead of pure cutting current resulted in a significant reduction of early bleeding without any consequence observed in terms of cannulation rate of the pancreatic orifice and post-ERCP pancreatitis rate [154]. Iwasaki et al. [169] in an RCT demonstrated that although both pure cutting current (autocut mode) and blended cutting current (endocut mode) have similar efficacy and safety for endoscopic papillectomy, the endocut mode may prevent immediate bleeding in cases with large tumor sizes. In this study, 60 patients were enrolled over a 2-year period. The incidences of delayed bleeding $(13.3 \%$ vs. $16.7 \%, P=1.00)$ and pancreatitis ( $27 \%$ vs. $30 \%, P=0.77$ ) were similar in the two groups. The rate of crush artefacts was higher in the endocut than in the autocut group ( $27 \%$ vs. $3.3 \%, P=0.03)$. Immediate bleeding when tumors greater than $14 \mathrm{~mm}$ in diameter were resected was more common in the autocut than in the endocut group ( $88 \%$ vs. $46 \%, P=0.04)$ [169].

\section{RECOMMENDATION}

ESGE suggests to perform biliary sphincterotomy and/or stenting after endoscopic papillectomy in cases of delayed biliary drainage, intraprocedural bleeding or high risk of early post-procedural bleeding, and intraductal extension of the neoplasm treated or not by complementary techniques.

Weak recommendation, very low quality evidence.

The use of biliary sphincterotomy varies in different retrospective trials, from being performed in the absence of free bile flow from the ostium after endoscopic papillectomy to routine performance $[21,25,80,86,148]$. Usually the rate of postendoscopic papillectomy cholangitis is very low [170]. However, 
in a retrospective case-control trial with procedure-related complications as the primary endpoint, the routine use of biliary sphincterotomy and stenting was associated with a lower rate of post-endoscopic papillectomy cholangitis, at $0 \%$ compared to $25 \%$ (although data about antibiotic prophylaxis were lacking) [154]. In the case of distal biliary intraductal growth that is possibly amenable to endoscopic resection, a maximum sphincterotomy can be performed to allow for complete resection using a smaller snare or an extraction balloon [147, 148, 171].

\section{Prevention and management of adverse events after endoscopic papillectomy}

\section{RECOMMENDATION}

ESGE recommends that the decision for prophylactic endoscopic hemostasis and the type of technique should be individualized.

Strong recommendation, very low quality evidence.

The role of prophylactic hemostasis was addressed in a retrospective comparative study with propensity matching [172] that evaluated the impact of adjunctive APC after endoscopic papillectomy on the risk of delayed bleeding. The delayed bleeding rate was significantly lower in the APC group compared to the non-APC group ( $7.3 \%$ vs. $31.7 \%$, OR 0.180, $P<0.01$ ). However, there are conflicting data: a recent RCT including 54 patients failed to find any reduction in the rate of delayed postpapillectomy bleeding with APC (30.8\% in the prophylactic APC group vs. $21.4 \%$ in the non-APC group; $P=0.434$ ) [173]. Ismail et al. [153] reported retrospectively that bleeding occurred post-papillectomy in $11 / 61$ (18\%) despite prophylactic APC having been performed in 10/11 of those who bled. Prophylactic clip application with closure of the frenulum has been proposed in small prospective case series to prevent delayed bleeding but data from larger and comparative studies are lacking [174]. An RCT by Hyun et al. that included 50 patients [156] reported that there was no difference in rate of post-papillectomy bleeding (early or delayed) when simple snare papillectomy was compared to papillectomy after submucosal injection of epinephrine (42.3\% [11/26] vs. $45.8 \%$ [11/24], respectively; $P=0.80)$.

\section{RECOMMENDATION}

ESGE suggests routine rectal administration of $100 \mathrm{mg}$ of diclofenac or indomethacin immediately before endoscopic papillectomy in all patients without contraindication to administration of nonsteroidal anti-inflammatory drugs.

Weak recommendation, low quality evidence.

\section{RECOMMENDATION}

ESGE recommends prophylactic pancreatic duct stenting to reduce the risk of pancreatitis after endoscopic papillectomy.

Strong recommendation, moderate quality evidence.

\section{RECOMMENDATION}

ESGE suggests, when prophylactic pancreatic duct stenting is not possible after endoscopic papillectomy, that other alternatives such as high volume hydration using lactated Ringer's solution can be considered in order to reduce the risk of post-ERCP pancreatitis.

Weak recommendation, low quality evidence.

Only prophylactic pancreatic duct stenting has been studied as a technique for prevention of pancreatitis after endoscopic papillectomy. The basis for this use is to prevent transient edema of the pancreatic orifice and occlusion from the effect of cautery, and to allow continued pancreatic duct drainage. One RCT with a sample size of only 19 patients has shown a significantly higher rate of pancreatitis in the unstented group (33\%) compared to none in the stented group $(P=0.02)$ [175]. A systematic review of 23 retrospective cohort studies demonstrated a statistically nonsignificant reduction in the rate of post-papillectomy pancreatitis (OR $0.71,95 \% \mathrm{Cl} 0.36-1.40 ; P=$ 0.325) [176]. The meta-analysis of Spadaccini et al. [26] has shown that the only factor affecting acute pancreatitis as an outcome was same-session prophylactic pancreatic stent placement (OR $-1.72,95 \% \mathrm{Cl}-2.95$ to $-0.50 ; P=0.006)$.

Endoscopic papillectomy would involve ERCP, in addition to snare resection of the major papilla. The direct impact of prophylactic measures against post-ERCP pancreatitis have not been evaluated, by extrapolation, to the case of endoscopic papillectomy. Nevertheless, meta-analyses that include RCTs have shown that pancreatic duct stenting [177], rectal nonsteroidal anti-inflammatory drugs [178], high volume peri-ERCP hydration [179], intravenous somatostatin [180], and sublingual glyceryl trinitrate [181] all reduce the incidence of post-ERCP pancreatitis. In the updated ESGE Guideline on ERCP-related adverse events, pancreatic duct stenting, rectal nonsteroidal anti-inflammatory drugs, and high volume hydration were recommended as measures for prophylaxis of post-ERCP pancreatitis [182]. In a secondary analysis of RCTs, failed pancreatic stent placement appeared to confer an increased risk of postERCP pancreatitis but this was attenuated by rectal indomethacin administration [183].

The presence of a pancreas divisum, which must be documented during the preoperative EUS and/or MRCP, avoids pancreatic stent placement, but should not be considered to be a substitute for prophylactic medical measures. 


\section{RECOMMENDATION}

ESGE recommends standard techniques for endoscopic hemostasis, such as epinephrine injection, electrocoagulation, endoscopic clip placement, noncontact hemostatic techniques, and argon plasma coagulation, for treatment of post-papillectomy bleeding.

Strong recommendation, low quality evidence.

\section{RECOMMENDATION}

ESGE recommends consideration of angiographic embolization in the case of massive bleeding unresponsive to endoscopic therapy.

Strong recommendation, very low quality evidence.

In their abovementioned meta-analysis, Spadaccini et al. [26] revealed a pooled rate of post-papillectomy bleeding of $10.6 \%\left(95 \% \mathrm{Cl} 5.2 \%-13.6 \% ; P^{2}=61 \%\right)$, with effective conservative management including endoscopic treatment for 149/156 events $(95.5 \%)$ for which data were available. In the more recent and largest retrospective studies, endoscopic treatments were performed in $69.1 \%$ of cases $(n=56 / 81)$ and mostly successfully $[20,39,41,88,89]$. Reported endoscopic techniques included epinephrine injection, electrocoagulation, clip application, and APC. In cases of endoscopic failure, patients underwent angiographic evaluation and embolization in 12 cases and in 1 a salvage surgery [20, 26, 39, 41, 88, 89]. One retrospective study reported the successful use of fibrin glue to achieve endoscopic hemostasis in refractory bleeding in 6 patients (3 post-papillectomy and 3 post-papillotomy) [184]. No comparative study is available, precluding the application of one technique in preference to another.

\section{Follow-up after endoscopic papillectomy}

\section{RECOMMENDATION}

ESGE recommends long-term monitoring of patients after endoscopic papillectomy or surgical ampullectomy, based on duodenoscopy with biopsies of the scar and of any abnormal area, within the first 3 months, at 6 and 12 months, and thereafter yearly for at least 5 years. Strong recommendation, low quality evidence.

No comparative study has analyzed the different strategies and procedures proposed for follow-up after endoscopic papillectomy.

The surveillance is usually based on duodenoscopy with biopsies taken from the scar and any abnormal area [23]. Rarely, EUS, $\mathrm{CT}$, and blood sampling have been performed in some series, without any clear superiority found compared with simple endoscopic monitoring $[19,103,185]$. EUS was performed systematically in one prospective series but did not facilitate highlighting recurrence [19]. In one single-center retrospective study, virtual chromoendoscopy (NBI) was compared to pathological information provided by biopsies and showed an interesting diagnostic performance (sensitivity $89 \%$, specificity $97 \%$, and negative predictive value $97 \%$ ) [23]. MRCP accuracy has not, to date, been evaluated during follow-up after endoscopic papillectomy.

Follow-up interval times commonly include a first endoscopic session within 3 months (mainly $4-8$ weeks) to allow retrieval of the prophylactic pancreatic stent $[19,20,37,39,41$, $88,89,103,105,140,185]$. Further sessions are scheduled at 6 -month intervals for the first year and yearly thereafter for up to 3 to 5 years. With this schema, the recurrence rate after endoscopic papillectomy was reported as $11.8 \%(95 \% \mathrm{Cl} 8.4-$ 16.5 ) in a recent literature review (23 studies, 1130 patients, follow-up 9.6-84.5 months) [26], and the median time to recurrence as 14.2 months (range 6-27) in another one including 967 patients [37]. This median period seems to be shorter in the case of adenoma confined to the papilla (9.2 months, interquartile range [IQR] 4.2-25.7) compared with LST-p (13.1 months, IQR 4.6-33.1) [20]. Furthermore, up to two thirds of recurrences are observed at the first follow-up session [39, 41]. On the other hand, a small number of patients developed delayed recurrence and adenocarcinoma after 5 years, warranting long-term and indefinite monitoring [20,85,89]. Finally, the vast majority of recurrences were benign and no interval cancer was described in the available literature in the setting of a well-established monitoring protocol.

\section{RECOMMENDATION}

ESGE recommends, in the case of recurrence after endoscopic papillectomy, careful assessment of local tumoral extent using endoscopic examination and biopsies, and EUS and MRCP investigations before any treatment. Strong recommendation, low quality evidence.

\section{RECOMMENDATION}

ESGE suggests that benign residual or recurrent lesions could be effectively managed by endoscopic treatment including ablative techniques (APC) and EMR.

Weak recommendation, low quality evidence.

The endoscopic management of post-papillectomy recurrence appears to be effective. In a systematic review, Spadaccini et al. [26] showed a substantial group of patients with recurrence who underwent further endoscopic management leading to oncological cure in $80.9 \%$ (95\% Cl $73 \%-87 \%$; pooled percentage) of cases (oncological cure was defined as complete excision regardless of number of sessions and of detection of recurrence if this had been amenable to endoscopic treatment). In recent large retrospective series, the efficacy of endoscopic retreatment after residual or recurring lesions varied from $38 \%$ to $100 \%$, with several sessions being required $[39,41,88,89,185]$. Tringali et al. [89] obtained successful outcomes among 39 pa- 
tients treated by EMR for residual or recurrent disease. Ablative treatment using APC has shown also interesting results $[39,88$, $89,185]$.

However, an increased rate of pancreatitis after APC for residual or recurrent disease has been found in some studies, prompting discussion of preventive measures such as pancreatic duct stenting [140].

Pancreatic stenting and biliary stenting could contribute to minimizing the risk of further stricture of the biliary or pancreatic orifice. The use of APC seems to have no impact on postpapillectomy duct stricture rate since patients systematically received pancreatic and/or biliary stenting if required [172].

\section{Disclaimer}

The legal disclaimer for ESGE guidelines [186] applies to this Guideline.

\section{Acknowledgments}

ESGE wishes to thank, for the added value they have brought to the final manuscript, the two external reviewers, Professor Schalk van der Merwe of the University Hospital-Gasthuisberg, University of Leuven, Belgium, and Dr. Udayakumar Navaneethan, Digestive Health Institute, Orlando, Florida, USA, and also Drs. Khalil Bedran, St George Hospital University Medical Center, Beirut, Lebanon, Marco Bustamente-Balén, La Fe University Hospital, Valencia, Spain, Gertran Rasschaert, Universitair Ziekenhuis Brussels, Belgium, and Suzane Ribeiro, Ghent University Hospital, Belgium for their comments.

\section{Competing interests}

M. Arvanitakis has received lecture fees from Olympus. T. Beyna provides consultancy to and gives lectures for Boston Scientific and Cook Medical (ongoing). J.E. van Hooft's department has received research grants from Cook Medical (from 2014 to 2019) and Abbott (from 2014 to 2017); she has received lecture fees from Medtronics (from 2014 to 2015, 2019) and Cook Medical (from 2019); she has received consultancy fees from Boston Scientific (from 2014 to 2017). G. Vanbiervliet has provided consultancy to Boston Scientific and Cook Medical (both from 2019 to present). A. Aelvoet, U. Arnelo, M. Barthet, O. Busch, P. Deprez, A. Larghi, G. Manes, A. Moss, B. Napoleon, M. Nayar,E. Pérez-Cuadrado-Robles, L. Kunovsky, S. Seewald, and M. Strijker, declare that they have no conflicts of interest.

\section{References}

[1] van Leerdam ME, Roos VH, van Hooft JE et al. Endoscopic management of polyposis syndromes: European Society of Gastrointestinal Endoscopy (ESGE) Guideline. Endoscopy 2019; 51: 877-895

[2] Ramai D, Ofosu A, Singh J et al. Demographics, tumor characteristics, treatment, and clinical outcomes of patients with ampullary cancer: a Surveillance, Epidemiology, and End Results (SEER) cohort study. Minerva Gastroenterol Dietol 2019; 65: 85-90

[3] Rostain F, Hamza S, Drouillard A et al. Trends in incidence and management of cancer of the ampulla of Vater. World J Gastroenterol 2014; 20: 10144-10150
[4] Van Dyke AL, Shiels MS, Jones GS et al. Biliary tract cancer incidence and trends in the United States by demographic group, 1999-2013. Cancer 2019; 125: 1489-1498

[5] Offerhaus G], Giardiello FM, Krush A] et al. The risk of upper gastrointestinal cancer in familial adenomatous polyposis. Gastroenterology 1992; 102: 1980-1982

[6] Fischer H-P, Zhou H. Pathogenesis of carcinoma of the papilla of Vater. J Hepatobiliary Pancreat Surg 2004; 11: 301-309

[7] Amin MB, Greene FL, Edge SB et al. The Eighth Edition AJCC Cancer Staging Manual: Continuing to build a bridge from a populationbased to a more "personalized" approach to cancer staging. CA Cancer J Clin 2017; 67: 93-99

[8] Imamura T, Yamamoto Y, Sugiura T et al. The prognostic relevance of the new 8th edition of the Union For International Cancer Control classification of TNM staging for ampulla of vater carcinoma. Ann Surg Oncol 2019; 26: 1639-1648

[9] Kim S], An S, Kang HJ et al. Validation of the eighth edition of the American Joint Committee on Cancer staging system for ampulla of Vater cancer. Surgery 2018; 163: 1071-1079

[10] Hester CA, Dogeas E, Augustine MM et al. Incidence and comparative outcomes of periampullary cancer: A population-based analysis demonstrating improved outcomes and increased use of adjuvant therapy from 2004 to 2012. J Surg Oncol 2019; 119: 303-317

[11] Nassour I, Mokdad AA, Minter RM et al. Racial and ethnic disparities in a national cohort of ampullary cancer patients. J Surg Oncol 2018; 117: 220-227

[12] Kimchi NA, Mindrul V, Broide E et al. The contribution of endoscopy and biopsy to the diagnosis of periampullary tumors. Endoscopy 1998; 30: 538-543

[13] Bisschops R, Areia M, Coron E et al. Performance measures for upper gastrointestinal endoscopy: a European Society of Gastrointestinal Endoscopy (ESGE) Quality Improvement Initiative. Endoscopy 2016; 48: 843-864

[14] Venu RP, Geenen JE. Diagnosis and treatment of diseases of the papilla. Clin Gastroenterol 1986; 15: 439-456

[15] Lee HS, Jang JS, Lee $S$ et al. Diagnostic accuracy of the initial endoscopy for ampullary tumors. Clin Endosc 2015; 48: 239-246

[16] Abdelhafez M, Phillip V, Hapfelmeier A et al. Cap assisted upper endoscopy for examination of the major duodenal papilla: a randomized, blinded, controlled crossover study (CAPPA Study). Am J Gastroenterol 2017; 112: 725-733

[17] Abdelhafez M, Phillip V, Hapfelmeier A et al. Comparison of capassisted endoscopy vs. side-viewing endoscopy for examination of the major duodenal papilla: a randomized, controlled, non-inferiority crossover study. Endoscopy 2019; 51: 419-426

[18] Shi X, Luo H, Ning B et al. Effect of cap-assisted esophagogastroduodenoscopy on examination of the major duodenal papilla: a noninferior, randomized controlled trial. Endoscopy 2019; 51: 427-435

[19] Napoleon B, Gincul R, Ponchon T et al. Endoscopic papillectomy for early ampullary tumors: long-term results from a large multicenter prospective study. Endoscopy 2014; 46: 127-134

[20] van der Wiel SE, Poley J-W, Koch AD et al. Endoscopic resection of advanced ampullary adenomas: a single-center 14-year retrospective cohort study. Surg Endosc 2019; 33: 1180-1188

[21] Irani S, Arai A, Ayub K et al. Papillectomy for ampullary neoplasm: results of a single referral center over a 10 -year period. Gastrointest Endosc 2009; 70: 923-932

[22] Ödemiş B, Durak MB, Cengiz M. Endoscopic ampullectomy of benign ampullary lesions: outcomes from a single center study. Surg Laparosc Endosc Percutan Tech 2020; 30: 270-275

[23] Klein A, Qi Z, Bahin FF et al. Outcomes after endoscopic resection of large laterally spreading lesions of the papilla and conventional ampullary adenomas are equivalent. Endoscopy 2018; 50: 972-983 
[24] Pérez-Cuadrado-Robles E, Piessevaux H, Moreels TG et al. Combined excision and ablation of ampullary tumors with biliary or pancreatic intraductal extension is effective even in malignant neoplasms. United Eur Gastroenterol J 2019; 7: 369-376

[25] Binmoeller KF, Boaventura S, Ramsperger K et al. Endoscopic snare excision of benign adenomas of the papilla of Vater. Gastrointest Endosc 1993; 39: 127-131

[26] Spadaccini M, Fugazza A, Frazzoni L et al. Endoscopic papillectomy for neoplastic ampullary lesions: A systematic review with pooled analysis. United Eur Gastroenterol J 2020; 8: 44-51

[27] Winter JM, Cameron JL, Olino K et al. Clinicopathologic analysis of ampullary neoplasms in 450 patients: implications for surgical strategy and long-term prognosis. J Gastrointest Surg 2010; 14: 379-387

[28] Patel V, Jowell P, Obando J et al. Does ampullary adenoma size predict invasion on EUS? Does invasion on EUS predict presence of malignancy? Endosc Int Open 2016; 4: E1313-E1318

[29] Uchiyama Y, Imazu H, Kakutani $\mathrm{H}$ et al. New approach to diagnosing ampullary tumors by magnifying endoscopy combined with a narrowband imaging system. J Gastroenterol 2006; 41: 483-490

[30] Park J-S, Seo D-W, Song T] et al. Usefulness of white-light imagingguided narrow-band imaging for the differential diagnosis of small ampullary lesions. Gastrointest Endosc 2015; 82: 94-101

[31] Itoi T, Tsuji S, Sofuni A et al. A novel approach emphasizing preoperative margin enhancement of tumor of the major duodenal papilla with narrow-band imaging in comparison to indigo carmine chromoendoscopy (with videos). Gastrointest Endosc 2009; 69: 136-141

[32] Yamaguchi K, Enjoji M, Kitamura K. Endoscopic biopsy has limited accuracy in diagnosis of ampullary tumors. Gastrointest Endosc 1990; 36: $588-592$

[33] Rodríguez C, Borda F, Elizalde I et al. How accurate is preoperative diagnosis by endoscopic biopsies in ampullary tumours? Rev Espanola Enfermedades Dig 2002; 94: 585-592

[34] Menzel J, Poremba C, Dietl KH et al. Tumors of the papilla of Vaterinadequate diagnostic impact of endoscopic forceps biopsies taken prior to and following sphincterotomy. Ann Oncol 1999; 10: 12271231

[35] Elek G, Gyôri S, Tóth B et al. Histological evaluation of preoperative biopsies from ampulla vateri. Pathol Oncol Res POR 2003; 9: 32-41

[36] Grobmyer SR, Stasik CN, Draganov P et al. Contemporary results with ampullectomy for 29 "benign" neoplasms of the ampulla. J Am Coll Surg 2008; 206: 466-471

[37] Laleman W, Verreth A, Topal B et al. Endoscopic resection of ampullary lesions: a single-center 8-year retrospective cohort study of 91 patients with long-term follow-up. Surg Endosc 2013; 27: 3865-3876

[38] Yamamoto K, Itoi T, Sofuni A et al. Expanding the indication of endoscopic papillectomy for T1a ampullary carcinoma. Dig Endosc 2019; 31: 188-196

[39] Li S, Wang Z, Cai F et al. New experience of endoscopic papillectomy for ampullary neoplasms. Surg Endosc 2019; 33: 612-619

[40] Kim H-N, Kim KM, Shin JU et al. Prediction of carcinoma after resection in subjects with ampullary adenomas on endoscopic biopsy. J Clin Gastroenterol 2013; 47: 346-351

[41] Alali A, Espino A, Moris M et al. Endoscopic resection of ampullary tumours: long-term outcomes and adverse events. J Can Assoc Gastroenterol 2020; 3: 17-25

[42] Mehta NA, Shah RS, Yoon J et al. Risks, benefits, and effects on management for biopsy of the papilla in patients with familial adenomatous polyposis. Clin Gastroenterol Hepatol 2020: doi:10.1016/j. cgh.2020.05.054

[43] Bourgeois N, Dunham F, Verhest A et al. Endoscopic biopsies of the papilla of Vater at the time of endoscopic sphincterotomy: difficulties in interpretation. Gastrointest Endosc 1984; 30: 163-166
[44] Leese T, Neoptolemos JP, West KP et al. Tumours and pseudotumours of the region of the ampulla of Vater: an endoscopic, clinical and pathological study. Gut 1986; 27: 1186-1192

[45] Ponchon T, Aucia N, Mitchell R et al. Biopsies of the ampullary region in patients suspected to have sphincter of Oddi dysfunction. Gastrointest Endosc 1995; 42: 296-300

[46] Defrain C, Chang CY, Srikureja W et al. Cytologic features and diagnostic pitfalls of primary ampullary tumors by endoscopic ultrasoundguided fine-needle aspiration biopsy. Cancer 2005; 105: 289-297

[47] Ogura T, Hara K, Hijioka S et al. Can endoscopic ultrasound-guided fine needle aspiration offer clinical benefit for tumors of the ampulla of vater? An initial study. Endosc Ultrasound 2012; 1: 84-89

[48] Kandler J, Neuhaus H. How to approach a patient with ampullary lesion. Gastroenterology 2018; 155: 1670-1676

[49] Zhou Y, Li D, Wu L et al. The histopathologic type predicts survival of patients with ampullary carcinoma after resection: A meta-analysis. Pancreatology 2017; 17: 273-278

[50] Ang DC, Shia J, Tang LH et al. The utility of immunohistochemistry in subtyping adenocarcinoma of the ampulla of vater. Am J Surg Pathol 2014; 38: 1371-1379

[51] Nagtegaal ID, Odze RD, Klimstra D et al. The 2019 WHO classification of tumours of the digestive system. Histopathology 2020; 76: 182188

[52] Gingras M-C, Covington K, Chang D et al. Ampullary cancers harbor ELF3 tumor suppressor gene mutations and exhibit frequent WNT dysregulation. Cell Rep 2016; 14: 907-919

[53] Perkins G, Svrcek M, Bouchet-Doumenq C et al. Can we classify ampullary tumours better? Clinical, pathological and molecular features. Results of an AGEO study. Br J Cancer 2019; 120: 697-702

[54] Yasuda K, Mukai H, Cho E et al. The use of endoscopic ultrasonography in the diagnosis and staging of carcinoma of the papilla of Vater. Endoscopy 1988; 20: (Suppl. 01): 218-222

[55] Mukai H, Nakajima M, Yasuda K et al. Evaluation of endoscopic ultrasonography in the pre-operative staging of carcinoma of the ampulla of Vater and common bile duct. Gastrointest Endosc 1992; 38: 676683

[56] Zhang QL, Nian WD, Zhang LP et al. Endoscopic ultrasonography assessment for ampullary and bile duct malignancy. Diagn Ther Endosc 1996; 03: 35-40

[57] Rattner DW, Fernandez-del Castillo C, Brugge WR et al. Defining the criteria for local resection of ampullary neoplasms. Arch Surg Chic III 1960 1996; 131: 366-371

[58] Tio TL, Sie LH, Kallimanis G et al. Staging of ampullary and pancreatic carcinoma: comparison between endosonography and surgery. Gastrointest Endosc 1996; 44: 706-713

[59] Quirk DM, Rattner DW, Fernandez-del Castillo C et al. The use of endoscopic ultrasonography to reduce the cost of treating ampullary tumors. Gastrointest Endosc 1997; 46: 334-337

[60] Itoh A, Goto H, Naitoh Y et al. Intraductal ultrasonography in diagnosing tumor extension of cancer of the papilla of Vater. Gastrointest Endosc 1997; 45: 251-260

[61] Sauvanet A, Chapuis O, Hammel P et al. Are endoscopic procedures able to predict the benignity of ampullary tumors? Am J Surg 1997; 174: $355-358$

[62] Cannon ME, Carpenter SL, Elta GH et al. EUS compared with CT, magnetic resonance imaging, and angiography and the influence of biliary stenting on staging accuracy of ampullary neoplasms. Gastrointest Endosc 1999; 50: 27-33

[63] Kubo H, Chijiiwa Y, Akahoshi K et al. Pre-operative staging of ampullary tumours by endoscopic ultrasound. Br J Radiol 1999; 72: 443-447

[64] Chen CH, Tseng LJ, Yang CC et al. Preoperative evaluation of periampullary tumors by endoscopic sonography, transabdominal sonogra- 
phy, and computed tomography. J Clin Ultrasound JCU 2001; 29: $313-$ 321

[65] Skordilis P, Mouzas IA, Dimoulios PD et al. Is endosonography an effective method for detection and local staging of the ampullary carcinoma? A prospective study. BMC Surg 2002; 2: 1

[66] Chen C-H, Yang C-C, Yeh Y-H et al. Reappraisal of endosonography of ampullary tumors: correlation with transabdominal sonography, $\mathrm{CT}$, and MRI. J Clin Ultrasound JCU 2009; 37: 18-25

[67] Artifon ELA, Couto DJ, Sakai P et al. Prospective evaluation of EUS versus CT scan for staging of ampullary cancer. Gastrointest Endosc 2009; 70: 290-296

[68] Manta R, Conigliaro R, Castellani D et al. Linear endoscopic ultrasonography vs magnetic resonance imaging in ampullary tumors. World J Gastroenterol 2010; 16: 5592-5597

[69] Wee E, Lakhtakia S, Gupta R et al. The diagnostic accuracy and strength of agreement between endoscopic ultrasound and histopathology in the staging of ampullary tumors. Indian J Gastroenterol 2012; 31: 324-332

[70] Trikudanathan G, Njei B, Attam R et al. Staging accuracy of ampullary tumors by endoscopic ultrasound: meta-analysis and systematic review. Dig Endosc 2014; 26: 617-626

[71] Okano N, Igarashi Y, Hara S et al. Endosonographic preoperative evaluation for tumors of the ampulla of vater using endoscopic ultrasonography and intraductal ultrasonography. Clin Endosc 2014; 47: 174-177

[72] Ridtitid W, Schmidt SE, Al-Haddad MA et al. Performance characteristics of EUS for locoregional evaluation of ampullary lesions. Gastrointest Endosc 2015; 81: 380-388

[73] Shen Z, Munker S, Zhou B et al. The accuracies of diagnosing pancreas divisum by magnetic resonance cholangiopancreatography and endoscopic ultrasound: a systematic review and meta-analysis. Sci Rep 2016; 6: 35389

[74] Ito K, Fujita N, Noda Y et al. Preoperative evaluation of ampullary neoplasm with EUS and transpapillary intraductal US: a prospective and histopathologically controlled study. Gastrointest Endosc 2007; 66: 740-747

[75] Heinzow HS, Lenz P, Lallier $S$ et al. Ampulla of Vater tumors: impact of intraductal ultrasound and transpapillary endoscopic biopsies on diagnostic accuracy and therapy. Acta Gastro-Enterol Belg 2011; 74: 509-515

[76] Meister T, Heinzow HS, Woestmeyer C et al. Intraductal ultrasound substantiates diagnostics of bile duct strictures of uncertain etiology. World J Gastroenterol 2013; 19: 874-881

[77] Heinzow HS, Kammerer S, Rammes $C$ et al. Comparative analysis of ERCP, IDUS, EUS and CT in predicting malignant bile duct strictures. World J Gastroenterol 2014; 20: 10495-10503

[78] Zádorová Z, Dvofák M, Hajer ]. Endoscopic therapy of benign tumors of the papilla of Vater. Endoscopy 2001; 33: 345-347

[79] Vogt M, Jakobs R, Benz C et al. Endoscopic therapy of adenomas of the papilla of Vater. A retrospective analysis with long-term follow-up. Dig Liver Dis 2000; 32: 339-345

[80] Catalano MF, Linder JD, Chak A et al. Endoscopic management of adenoma of the major duodenal papilla. Gastrointest Endosc 2004; 59: 225-232

[81] Jeanniard-Malet O, Caillol F, Pesenti C et al. Short-term results of 42 endoscopic ampullectomies: a single-center experience. Scand J Gastroenterol 2011; 46: 1014-1019

[82] Ahn D-W, Ryu JK, Kim J et al. Endoscopic papillectomy for benign ampullary neoplasms: how can treatment outcome be predicted? Gut Liver 2013; 7: 239-245

[83] Attila T, Parlak E, Alper E et al. Endoscopic papillectomy of benign ampullary lesions: Outcomes from a multicenter study. Turk J Gastroenterol 2018; 29: 325-334
[84] De Palma GD, Luglio G, Maione F et al. Endoscopic snare papillectomy: a single institutional experience of a standardized technique. A retrospective cohort study. . Int J Surg Lond Engl 2015; 13: 180-183

[85] Ridtitid W, Tan D, Schmidt SE et al. Endoscopic papillectomy: risk factors for incomplete resection and recurrence during long-term follow-up. Gastrointest Endosc 2014; 79: 289-296

[86] Cheng C-L, Sherman S, Fogel EL et al. Endoscopic snare papillectomy for tumors of the duodenal papillae. Gastrointest Endosc 2004; 60: 757-764

[87] Tsuji S, Itoi T, Sofuni A et al. Tips and tricks in endoscopic papillectomy of ampullary tumors: single-center experience with large case series (with videos). J Hepatobiliary Pancreat Sci 2015; 22: E22-E27

[88] Sahar N, Krishnamoorthi R, Kozarek RA et al. Long-term outcomes of endoscopic papillectomy for ampullary adenomas. Dig Dis Sci 2020; 65: 260-268

[89] Tringali A, Valerii G, Boškoski I et al. Endoscopic snare papillectomy for adenoma of the ampulla of vater: Long-term results in 135 consecutive patients. Dig Liver Dis 2020; 52: 1033-1038

[90] Lee R, Huelsen A, Gupta S et al. Endoscopic ampullectomy for noninvasive ampullary lesions: a single-center 10-year retrospective cohort study. Surg Endosc 2021; 35: 684-692

[91] Gracient A, Delcenserie R, Chatelain D et al. Endoscopic or surgical ampullectomy for intramucosal ampullary tumor: the patient populations are not the same. J Visc Surg 2020; 157: 183-191

[92] Nappo G, Gentile D, Galvanin J et al. Trans-duodenal ampullectomy for ampullary neoplasms: early and long-term outcomes in 36 consecutive patients. Surg Endosc 2020; 34: 4358-4368

[93] Mendonça EQ, Bernardo WM, de Moura EGH et al. Endoscopic versus surgical treatment of ampullary adenomas: a systematic review and meta-analysis. Clin Sao Paulo Braz 2016; 71: 28-35

[94] Ceppa EP, Burbridge RA, Rialon KL et al. Endoscopic versus surgical ampullectomy: an algorithm to treat disease of the ampulla of Vater. Ann Surg 2013; 257: 315-322

[95] Dubois M, Labgaa I, Dorta G et al. Endoscopic and surgical ampullectomy for non-invasive ampullary tumors: Short-term outcomes. Biosci Trends 2017; 10: 507-511

[96] Sauvanet A, Dokmak S, Cros J et al. Surgical ampullectomy with complete resection of the common bile duct: a new procedure for radical resection of non-invasive ampulloma with biliary extension. J Gastrointest Surg 2017; 21: 1533-1539

[97] Yamamoto K, Sofuni A, Tsuchiya T et al. Clinical impact of piecemeal resection concerning the lateral spread of ampullary adenomas. Intern Med 2019; 58: 901-906

[98] Yoon Y-S, Kim S-W, Park S] et al. Clinicopathologic analysis of early ampullary cancers with a focus on the feasibility of ampullectomy. Ann Surg 2005; 242: 92-100

[99] Hsu H-P, Yang T-M, Hsieh Y-H et al. Predictors for patterns of failure after pancreaticoduodenectomy in ampullary cancer. Ann Surg Oncol 2007; 14: 50-60

[100] Lee H, Park JY, Kwon W et al. Transduodenal ampullectomy for the treatment of early-stage ampulla of vater cancer. World J Surg 2016; 40: 967-973

[101] Kawabata Y, Ishikawa N, Moriyama I et al. What is an adequate surgical management for $\mathrm{pT}$ is and $\mathrm{PT} 1$ early ampullary carcinoma? Hepatogastroenterology 2014; 61: 12-17

[102] Yamao T, Isomoto $\mathrm{H}$, Kohno $\mathrm{S}$ et al. Endoscopic snare papillectomy with biliary and pancreatic stent placement for tumors of the major duodenal papilla. Surg Endosc 2010; 24: 119-124

[103] Alvarez-Sanchez M-V, Oria I, Luna OB et al. Can endoscopic papillectomy be curative for early ampullary adenocarcinoma of the ampulla of Vater? Surg Endosc 2017; 31: 1564-1572 
[104] Yoon SM, Kim M-H, Kim M] et al. Focal early stage cancer in ampullary adenoma: surgery or endoscopic papillectomy? Gastrointest Endosc 2007; 66: 701-707

[105] Salmi S, Ezzedine S, Vitton V et al. Can papillary carcinomas be treated by endoscopic ampullectomy? Surg Endosc 2012; 26: 920 925

[106] Gao Y, Zhu Y, Huang X et al. Transduodenal ampullectomy provides a less invasive technique to cure early ampullary cancer. BMC Surg 2016; $16: 36$

[107] Song J, Liu H, Li Z et al. Long-term prognosis of surgical treatment for early ampullary cancers and implications for local ampullectomy. BMC Surg 2015; 15: 32

[108] Hornick JR, Johnston FM, Simon PO et al. A single-institution review of 157 patients presenting with benign and malignant tumors of the ampulla of Vater: management and outcomes. Surgery 2011; 150: 169-176

[109] Beger HG, Treitschke F, Gansauge F et al. Tumor of the ampulla of Vater: experience with local or radical resection in 171 consecutively treated patients. Arch Surg 1999; 134: 526-532

[110] Dumonceau J-M, Tringali A, Papanikolaou IS et al. Endoscopic biliary stenting: indications, choice of stents, and results: European Society of Gastrointestinal Endoscopy (ESGE) Clinical Guideline - Updated October 2017. Endoscopy 2018; 50: 910-930

[111] Inamdar S, Slattery E, Bhalla R et al. Comparison of adverse events for endoscopic vs percutaneous biliary drainage in the treatment of malignant biliary tract obstruction in an inpatient national cohort. JAMA Oncol 2016; 2: 112-117

[112] Duan F, Cui L, Bai Y et al. Comparison of efficacy and complications of endoscopic and percutaneous biliary drainage in malignant obstructive jaundice: a systematic review and meta-analysis. Cancer Imaging 2017; 17: 27

[113] Moole H, Bechtold ML, Forcione D et al. A meta-analysis and systematic review: Success of endoscopic ultrasound guided biliary stenting in patients with inoperable malignant biliary strictures and a failed ERCP. Medicine (Baltimore) 2017; 96: e5154

[114] Wang K, Zhu J, Xing L et al. Assessment of efficacy and safety of EUSguided biliary drainage: a systematic review. Gastrointest Endosc 2016; 83: 1218-1227

[115] Khan MA, Akbar A, Baron TH et al. Endoscopic ultrasound-guided biliary drainage: a systematic review and meta-analysis. Dig Dis Sci 2016; 61: 684-703

[116] Bishay K, Boyne D, Yaghoobi M et al. Endoscopic ultrasound-guided transmural approach versus ERCP-guided transpapillary approach for primary decompression of malignant biliary obstruction: a metaanalysis. Endoscopy 2019; 51: 950-960

[117] Hathorn KE, Bazarbashi AN, Sack JS et al. EUS-guided biliary drainage is equivalent to ERCP for primary treatment of malignant distal biliary obstruction: a systematic review and meta-analysis. Endosc Int Open 2019; 7: E1432-E1441

[118] Jin Z, Wei Y, Lin $\mathrm{H}$ et al. Endoscopic ultrasound-guided versus endoscopic retrograde cholangiopancreatography-guided biliary drainage for primary treatment of distal malignant biliary obstruction: A systematic review and meta-analysis. Dig Endosc 2020; 32: 16-26

[119] Li D-F, Zhou C-H, Wang L-S et al. Is ERCP-BD or EUS-BD the preferred decompression modality for malignant distal biliary obstruction? A meta-analysis of randomized controlled trials. Rev Espanola Enfermedades Dig 2019; 111: 953-960

[120] Logiudice FP, Bernardo WM, Galetti F et al. Endoscopic ultrasoundguided vs endoscopic retrograde cholangiopancreatography biliary drainage for obstructed distal malignant biliary strictures: A systematic review and meta-analysis. World J Gastrointest Endosc 2019; 11: 281-291
[121] Lou X, Yu D, Li ] et al. Efficacy of endoscopic ultrasound-guided and endoscopic retrograde cholangiopancreatography-guided biliary drainage for malignant biliary obstruction: a systematic review and meta-analysis. Minerva Med 2019; 110: 564-574

[122] Miller CS, Barkun AN, Martel M et al. Endoscopic ultrasound-guided biliary drainage for distal malignant obstruction: a systematic review and meta-analysis of randomized trials. Endosc Int Open 2019; 7: E1563-E1573

[123] Han SY, Kim S-O, So H et al. EUS-guided biliary drainage versus ERCP for first-line palliation of malignant distal biliary obstruction: A systematic review and meta-analysis. Sci Rep 2019; 9: 16551

[124] Bernon MM, Shaw J, Burmeister $S$ et al. Distal malignant biliary obstruction: a prospective randomised trial comparing plastic and uncovered self-expanding metal stents in the palliation of symptomatic jaundice. South Afr J Surg 2018; 56: 30-34

[125] Yuan T-W, Liu H-Q, Wang S-B et al. Comparison of plastic stents with self-expandable metal stents in palliative treatment of malignant biliary obstruction: a meta-analysis. Eur Rev Med Pharmacol Sci 2017; 21: 2847-2857

[126] Tringali A, Hassan C, Rota M et al. Covered vs. uncovered selfexpandable metal stents for malignant distal biliary strictures: a systematic review and meta-analysis. Endoscopy 2018; 50: 631-641

[127] Conio M, Mangiavillano B, Caruso A et al. Covered versus uncovered self-expandable metal stent for palliation of primary malignant extrahepatic biliary strictures: a randomized multicenter study. Gastrointest Endosc 2018; 88: 283-291.e3

[128] Dhondt E, Vanlangenhove P, De Man M et al. No advantage of expanded polytetrafluoroethylene and fluorinated ethylene propylene-covered stents over uncovered nitinol stents for percutaneous palliation of malignant infrahilar biliary obstruction: results of a single-center prospective randomized trial. J Vasc Interv Radiol JVIR 2020; 31: 82-92

[129] Lee PJ, Podugu A, Wu D et al. Preoperative biliary drainage in resectable pancreatic cancer: a systematic review and network meta-analysis. HPB 2018; 20: 477-486

[130] Barauskas G, Urbonas K, Smailyte G et al. Preoperative endoscopic biliary drainage may negatively impact survival following pancreatoduodenectomy for ampullary cancer. Dig Surg 2016; 33: 462-469

[131] Bourgouin S, Ewald J, Mancini ] et al. Disease-free survival following resection in non-ductal periampullary cancers: A retrospective multicenter analysis. Int J Surg 2017; 42: 103-109

[132] Wu J-M, Ho T-W, Yen H-H et al. Endoscopic retrograde biliary drainage causes intra-abdominal abscess in pancreaticoduodenectomy patients: an important but neglected risk factor. Ann Surg Oncol 2019; 26: 1086-1092

[133] Miura F, Sano K, Wada K et al. Prognostic impact of type of preoperative biliary drainage in patients with distal cholangiocarcinoma. Am J Surg 2017; 214: 256-261

[134] Strom TJ, Klapman JB, Springett GM et al. Comparative long-term outcomes of upfront resected pancreatic cancer after preoperative biliary drainage. Surg Endosc 2015; 29: 3273-3281

[135] Uemura K, Murakami Y, Satoi S et al. Impact of preoperative biliary drainage on long-term survival in resected pancreatic ductal adenocarcinoma: a multicenter observational study. Ann Surg Oncol 2015; 22: (Suppl. 03): S1238-1246

[136] Wang L, Lin N, Xin F et al. A systematic review of the comparison of the incidence of seeding metastasis between endoscopic biliary drainage and percutaneous transhepatic biliary drainage for resectable malignant biliary obstruction. World J Surg Oncol 2019; 17: 116

[137] Crippa S, Cirocchi R, Partelli S et al. Systematic review and metaanalysis of metal versus plastic stents for preoperative biliary drainage in resectable periampullary or pancreatic head tumors. Eur J Surg Oncol J 2016; 42: 1278-1285 
[138] Liu P, Lin H, Chen Y et al. Comparison of metal and plastic stents for preoperative biliary drainage in resectable and borderline resectable periampullary cancer: a meta-analysis and system review. J Laparoendosc Adv Surg Tech A 2018; 28: 1074-1082

[139] Boix J, Lorenzo-Zúñiga V, Moreno de Vega V et al. Endoscopic resection of ampullary tumors: 12-year review of 21 cases. Surg Endosc 2009; 23: 45-49

[140] Bohnacker S, Seitz U, Nguyen D et al. Endoscopic resection of benign tumors of the duodenal papilla without and with intraductal growth. Gastrointest Endosc 2005; 62: 551-560

[141] Suarez AL, Coté GA, Elmunzer BJ. Adjunctive radiofrequency ablation for the endoscopic treatment of ampullary lesions with intraductal extension (with video). Endosc Int Open 2016; 4: E748-751

[142] Rustagi T, Irani S, Reddy DN et al. Radiofrequency ablation for intraductal extension of ampullary neoplasms. Gastrointest Endosc 2017; 86: 170-176

[143] Camus M, Napoléon B, Vienne A et al. Efficacy and safety of endobiliary radiofrequency ablation for the eradication of residual neoplasia after endoscopic papillectomy: a multicenter prospective study. Gastrointest Endosc 2018; 88: 511-518

[144] Monson JR, Donohue JH, McEntee GP et al. Radical resection for carcinoma of the ampulla of Vater. Arch Surg 1991; 126: 353-357

[145] Desilets DJ, Dy RM, Ku PM et al. Endoscopic management of tumors of the major duodenal papilla: Refined techniques to improve outcome and avoid complications. Gastrointest Endosc 2001; 54: 202208

[146] Ardengh JC, Kemp R, Lima-Filho ÉR et al. Endoscopic papillectomy: The limits of the indication, technique and results. World J Gastrointest Endosc 2015; 7: 987-994

[147] Bassan M, Bourke M. Endoscopic ampullectomy: a practical guide. J Interv Gastroenterol 2012; 2: 23-30

[148] Bohnacker S, Soehendra N, Maguchi $\mathrm{H}$ et al. Endoscopic resection of benign tumors of the papilla of vater. Endoscopy 2006; 38: 521-525

[149] Espinel J, Pinedo E, Ojeda V et al. Endoscopic ampullectomy: a technical review. Rev Esp Enferm Dig 2016; 108: 271-278

[150] Patel R, Varadarajulu S, Wilcox CM. Endoscopic ampullectomy: techniques and outcomes. J Clin Gastroenterol 2012; 46: 8-15

[151] Han J, Kim M-H. Endoscopic papillectomy for adenomas of the major duodenal papilla (with video). Gastrointest Endosc 2006; 63: 292 301

[152] Heinzow HS, Lenz P, Lenze F et al. Feasibility of snare papillectomy in ampulla of Vater tumors: meta-analysis and study results from a tertiary referral center. Hepatogastroenterology 2012; 59: 332-335

[153] Ismail S, Udd M, Heikki J et al. Endoscopic papillectomy, singlecentre experience. Surg Endosc 2014; 28: 3234-3239

[154] Ito K, Fujita N, Noda Y et al. Impact of technical modification of endoscopic papillectomy for ampullary neoplasm on the occurrence of complications. Dig Endosc 2012; 24: 30-35

[155] Menees SB, Schoenfeld P, Kim HM et al. A survey of ampullectomy practices. World J Gastroenterol 2009; 15: 3486-3492

[156] Hyun J, Lee T, Park J et al. A prospective multicenter study of submucosal injection to improve endoscopic snare papillectomy for ampullary adenoma. Gastrointest Endosc 2017; 85: 746-755

[157] Chung KH, Lee SH, Choi JH et al. Effect of submucosal injection in endoscopic papillectomy of ampullary tumor: Propensity-score matching analysis. United Eur Gastroenterol J 2018; 6: 576-585

[158] Lee SK, Kim M-H, Seo DW et al. Endoscopic sphincterotomy and pancreatic duct stent placement before endoscopic papillectomy: are they necessary and safe procedures? Gastrointest Endosc 2002; 55: 302-304
[159] Alexander S, Bourke M], Williams S] et al. EMR of large, sessile, sporadic nonampullary duodenal adenomas: technical aspects and long-term outcome (with videos). Gastrointest Endosc 2009; 69: 66-73

[160] Fanning SB, Bourke MJ, Williams S] et al. Giant laterally spreading tumors of the duodenum: endoscopic resection outcomes, limitations, and caveats. Gastrointest Endosc 2012; 75: 805-812

[161] Navaneethan U, Lourdusamy D, Mehta D et al. Endoscopic resection of large sporadic non-ampullary duodenal polyps: efficacy and longterm recurrence. Surg Endosc 2014; 28: 2616-2622

[162] Singh A, Siddiqui UD, Konda VJ et al. Safety and efficacy of EMR for sporadic, nonampullary duodenal adenomas: a single U.S. center experience (with video). Gastrointest Endosc 2016; 84: 700-708

[163] Hoteya S, Furuhata T, Takahito T et al. Endoscopic submucosal dissection and endoscopic mucosal resection for non-ampullary superficial duodenal tumor. Digestion 2017; 95: 36-42

[164] Bartel M], Puri R, Brahmbhatt B et al. Endoscopic and surgical management of nonampullary duodenal neoplasms. Surg Endosc 2018; 32: 2859-2869

[165] Ferlitsch M, Moss A, Hassan C et al. Colorectal polypectomy and endoscopic mucosal resection (EMR): European Society of Gastrointestinal Endoscopy (ESGE) Clinical Guideline. Endoscopy 2017; 49 270-297

[166] Klein A, Nayyar D, Bahin FF et al. Endoscopic mucosal resection of large and giant lateral spreading lesions of the duodenum: success, adverse events and long-term outcomes. Gastrointest Endosc 2016 84: 688-696

[167] Klein A, Tutticci N, Bourke M]. Endoscopic resection of advanced and laterally spreading duodenal papillary tumors. Dig Endosc 2016; 28: 121-130

[168] Minami K, Iwasaki E, Fukuhara S et al. Electric endocut and autocut resection for endoscopic papillectomy: a systematic review. Intern Med 2019; 58: 2767-2772

[169] Iwasaki E, Minami K, Itoi T et al. Impact of electrical pulse cut mode during endoscopic papillectomy: Pilot randomized clinical trial. Dig Endosc 2020; 32: 127-135

[170] El Hajj II, Coté GA. Endoscopic diagnosis and management of ampullary lesions. Gastrointest Endosc Clin N Am 2013; 23: 95-109

[171] Norton ID, Gostout C], Baron TH et al. Safety and outcome of endoscopic snare excision of the major duodenal papilla. Gastrointest Endosc 2002; 56: 239-243

[172] Nam K, Song T], Kim RE et al. Usefulness of argon plasma coagulation ablation subsequent to endoscopic snare papillectomy for ampullary adenoma. Dig Endosc 2018; 30: 485-492

[173] Yang JK, Hyun J], Lee TH et al. Can prophylactic argon plasma coagulation reduce delayed post-papillectomy bleeding? A prospective multicenter trial. J Gastroenterol Hepatol 2021; 36: 467-473

[174] Kagawa K, Kubota K, Kurita Y et al. Effect of preventive closure of the frenulum after endoscopic papillectomy: A prospective pilot study. J Gastroenterol Hepatol 2020; 35: 374-379

[175] Harewood GC, Pochron NL, Gostout C]. Prospective, randomized, controlled trial of prophylactic pancreatic stent placement for endoscopic snare excision of the duodenal ampulla. Gastrointest Endosc 2005; 62: 367-370

[176] Wang Y, Qi M, Hao Y et al. The efficacy of prophylactic pancreatic stents against complications of post-endoscopic papillectomy or endoscopic ampullectomy: a systematic review and meta-analysis. Ther Adv Gastroenterol 2019: doi:10.1177/1756284819855342

[177] Mazaki T, Mado K, Masuda $\mathrm{H}$ et al. Prophylactic pancreatic stent placement and post-ERCP pancreatitis: an updated meta-analysis. J Gastroenterol 2014; 49: 343-355 
[178] Patai Á, Solymosi N, Mohácsi L et al. Indomethacin and diclofenac in the prevention of post-ERCP pancreatitis: a systematic review and meta-analysis of prospective controlled trials. Gastrointest Endosc 2017; 85: 1144-1156.e1

[179] Radadiya D, Devani K, Arora S et al. Peri-procedural aggressive hydration for post endoscopic retrograde cholangiopancreatography (ERCP) pancreatitis prophylaxsis: meta-analysis of randomized controlled trials. Pancreatology 2019; 19: 819-827

[180] Wang G, Xiao G, Xu L et al. Effect of somatostatin on prevention of post-endoscopic retrograde cholangiopancreatography pancreatitis and hyperamylasemia: A systematic review and meta-analysis. Pancreatology 2018; 18: 370-378

[181] Ding J, Jin X, Pan Y et al. Glyceryl trinitrate for prevention of postERCP pancreatitis and improve the rate of cannulation: a meta-analysis of prospective, randomized, controlled trials. PloS One 2013; 8 : e75645
[182] Dumonceau J-M, Kapral C, Aabakken L et al. ERCP-related adverse events: European Society of Gastrointestinal Endoscopy (ESGE) Guideline. Endoscopy 2020; 52: 127-149

[183] Choksi N, Elmunzer BJ, Stidham RW et al. Cold snare piecemeal resection of colonic and duodenal polyps $\geq 1 \mathrm{~cm}$. Endosc Int Open 2015; 3: E508-513

[184] Mutignani M, Seerden T, Tringali A et al. Endoscopic hemostasis with fibrin glue for refractory postsphincterotomy and postpapillectomy bleeding. Gastrointest Endosc 2010; 71: 856-860

[185] Sakai A, Tsujimae M, Masuda A et al. Clinical outcomes of ampullary neoplasms in resected margin positive or uncertain cases after endoscopic papillectomy. World J Gastroenterol 2019; 25: 13871397

[186] Hassan C, Ponchon T, Bisschops R et al. European Society of Gastrointestinal Endoscopy (ESGE) Publications Policy - Update 2020. Endoscopy 2020; 52: 123-126 